\title{
A RESEARCH COMBINES NONDESTRUCTIVE TESTING AND A NEURO- FUZZY SYSTEM FOR EVALUATING RIGID PAVEMENT FAILURE POTENTIAL
}

Shuh-Gi Chern

Professor, Department of Harbor and River Engineering, National Taiwan Ocean University, Keelung, Taiwan 202,

R.O.C., sgchern@mail.ntou.edu.tw

Yu-Shih Lee

Ph.D. Candidate, Department of Harbor and River Engineering, National Taiwan Ocean University, Keelung, Taiwan 202, R.O.C

Rong-Feng $\mathrm{Hu}$

Assistant Professor, Department of Air Transportation, Kainau University, Luzhu Taoyuan, Taiwan 338, R.O.C

Yen-Jen Chang

Graduate Student, Department of Harbor and River Engineering, National Taiwan Ocean University, Keelung, Taiwan, R.O.C.

Follow this and additional works at: https://jmstt.ntou.edu.tw/journal

Part of the Civil and Environmental Engineering Commons

\section{Recommended Citation}

Chern, Shuh-Gi; Lee, Yu-Shih; Hu, Rong-Feng; and Chang, Yen-Jen (2005) "A RESEARCH COMBINES NONDESTRUCTIVE TESTING AND A NEURO-FUZZY SYSTEM FOR EVALUATING RIGID PAVEMENT FAILURE POTENTIAL," Journal of Marine Science and Technology. Vol. 13: Iss. 2, Article 9.

DOI: 10.51400/2709-6998.2114

Available at: https://jmstt.ntou.edu.tw/journal/vol13/iss2/9

This Research Article is brought to you for free and open access by Journal of Marine Science and Technology. It has been accepted for inclusion in Journal of Marine Science and Technology by an authorized editor of Journal of Marine Science and Technology. 


\section{A RESEARCH COMBINES NONDESTRUCTIVE TESTING AND A NEURO-FUZZY}

SYSTEM FOR EVALUATING RIGID PAVEMENT FAILURE POTENTIAL

\section{Acknowledgements}

The authors would to thank the supports of the Chiang Kai-Shek International airport authority for their data and serves that were used in this research. 


\title{
A RESEARCH COMBINES NONDESTRUCTIVE TESTING AND A NEURO-FUZZY SYSTEM FOR EVALUATING RIGID PAVEMENT FAILURE POTENTIAL
}

\author{
Shuh-Gi Chern*, Yu-Shih Lee**, Rong-Feng Hu***, and Yen-Jen Chang****
}

\begin{abstract}
Key words: non-destructive testing (NDT), heavy-falling weight deflectometer (HWD), pavement condition index (PCI), neurofuzzy system.
\end{abstract}

\begin{abstract}
In recent years, advances in hardware and software technology had brought to significant improvement of NDT (Non-Destructive Test) equipment. In the field of evaluation and designs for the airfield pavement, NDT has been extensively used. NDT is an efficient methodology for assessing the structural condition of an airfield pavement, in the meantime, engineers need to carry other methods for assessing pavement performance, such as visual condition, roughness, and friction characteristics in completing the overall pavement evaluation. In this research, a model combined neuro-fuzzy system, PCI method (pavement condition index, visual inspection) and NDT (Heavy Falling Weight Deflectometer, HWD, structural condition) data are used to evaluate an airfield pavement potential distress. With the help of case studies, it is shown that the proposed model is capable to predict possible area of pavement damage potentials.
\end{abstract}

\section{INTRODUCTION}

Before NDT technology had been developed, pavement structural data must be obtained from many borings, cores, and excavation pits on an existing airfield pavement, those works will be disruptive to airport operations. For example, to conduct a plate load test in order to get in-situ modulus of subgrade reaction $k$ of a jointed plain Portland Cement Concrete (PCC), it needs a $1.2 \mathrm{~m}$ by $1.8 \mathrm{~m}$ pits, and needs to remove each

Paper Submitted 05/12/04, Accepted 06/01/04. Author for Correspondence: Shuh-Gi Chern. E-mail: sgchern@mail.ntou.edu.tw.

*Professor, Department of Harbor and River Engineering, National Taiwan Ocean University, Keelung, Taiwan 202, R.O.C.

**Ph.D. Candidate, Department of Harbor and River Engineering, National Taiwan Ocean University, Keelung, Taiwan 202, R.O.C.

***Assistant Professor, Department of Air Transportation, Kainau University, Luzhu Taoyuan, Taiwan 338, R.O.C.

****Graduate Student, Department of Harbor and River Engineering, National Taiwan Ocean University, Keelung, Taiwan, R.O.C. pavement layer until the subgrade is exposed. After the plate-bearing test is completed, it would then need to spend a lot of money to repair the test pit, and may keep the test area closed for several days [13, 24]. In recent years, advances in hardware and software technology had brought to significant improvement of NDT (Nondestructive test) equipment. And NDT has been extensively used in the field of evaluation and designs for the highways and airfield pavement $[2,4-7,15,18$, $19,23,25,26]$. There are many advantages in using NDT which could replace or supplement traditional destructive tests in the airfield, under close contact with Air Traffic Control, it will then eliminate the interference with the operation of airport. The record shows that NDT (FWD) operation can obtain in-situ structural data within 2 to 3 minutes. On regular highway (mainly with Asphalt Concrete pavement) may collect FWD data up to 250 locations per day.

HWD testing is an efficient methodology for assessing the structural condition of an airfield pavement, in the meantime, engineers need to carry other methods for assessing pavement performance, such as PCI (Pavement Condition Index) [3, 11, 21], GPR (Ground Penetrating Radar) [25, 26], roughness, and friction characteristics in completing the overall pavement evaluation. PCI method was widely used in the earlier stage to evaluate the pavement condition. However, limitation of PCI data is that the systems have a tendency to determine PCI values which does not really describe the distress type during visual inspection procedures, as is well known, it is possible to have two pieces of pavement with the same PCI value, but totally different distress types.

For developing a pavement maintenance and rehabilitation strategy, the correlation between structural and functional performances is important. For example, due to environmental distress, a pavement may have a low PCI value, but it still has sufficient strength to accommodate structural loading. It would be essential 
to cross check the NDT (FWD) data with PCI value, so as to determine the structural analysis when maintenance works are necessary. A pavement having load related distress would then be repaired with structural overlay or re-construction; and a pavement with severe raveling without load related damage could have a patching, seal coat or minor overlay. An efficient pavement management not only makes engineering progresses but also economic savings.

Because of the wide range of pavement types, loading and local environmental conditions, there are so many parameters influence the pavement performance, it seems that a neuro-fuzzy system may solve this complex problems. In fact, the neuro-fuzzy system had successfully to analysis different problems in civil engineering field, such as the driven piles [1], the stressstrain modeling of sands [10], the liquefaction potential $[8,12,17,22]$ and the slope failure potential $[16,20]$.

In this research a neuro-fuzzy system is attempted to solve this problems, the PCI investigating record data as well as Heavy-Falling Weight Deflectometer (HWD) data are used to evaluate pavement strength condition that induced pavement damage potentials. In the case study, it is shown that the proposed model is able to predict pavement damage potentials.

\section{OVERVIEW OF NEURAL NETWORKS}

A neural network consists of a number of interconnected proceeding units commonly referred to as neurodes or neurons. Each neuron receives an input signal from neurons to which it is connected. Each of these connections has numerical weights associated with it. These weights determine the nature and strength of the influence between the interconnected neurons. The signals from each input are then processed through a weighted sum of the inputs, and the processed output signal is then transmitted to another neuron via a transfer or activation function. A typical transfer function is the sigmoid transfer function. The sigmoid function modulates the weight sum of the inputs so that the output approaches unity when the input gets larger and approaches zero when the input gets smaller.

Figure 1 shows the architecture of a typical neural network consisting of conventional three layers of interconnected neurons. Each neuron is connected to all the neurons in the next layer. There is an input layer that holds the response of the network to the input. It is the intermediate layers, also known as hidden layers that enable these networks to respect and compute complicated associations between patterns. A single hidden layer is common used in most conventional neural networks.

Training of the neural network is essentially car- ried out through the presentation of a series of example patterns of associated input and output values. The neural network learns what it is to compute through the modification of the weight of the interconnected neurons. Among many learning systems, back-propagation model is the most commonly used one. The learning algorithm processes the patterns in two stages. In the first stage, the input pattern generates a forward flow of signals from the input layer to the output layer. The error of each output neuron is then computed from the difference between the computed and the desired output. The second stage involves the readjustment of the weights in hidden and output layers to reduce the difference between the actual and desired output. Training is carried out iteratively until the root mean squared errors (RMSE) over all training patterns are minimized.

Once the training phase is computed satisfactorily, verification of the performance of the neural network is then carried out the using patterns that were not included in the training set. It will then determine the quality of the predictions in comparison to the desired outputs. This is often called the testing phase. No additional learning occurs during this phase.

Before presenting the input patterns to the neural network, some preprocessing of the data is necessary. This usually involves scaling or normalization of the input patterns to values in the range 0 to 1 . This is required because the sigmoid transfer function modulates the output to values between 0 and 1 .

\section{The structure of neuro-fuzzy system}

Figure 2 shows the structure of fuzzy system, consisting of fuzzification, fuzzy rule base, fuzzy infer-

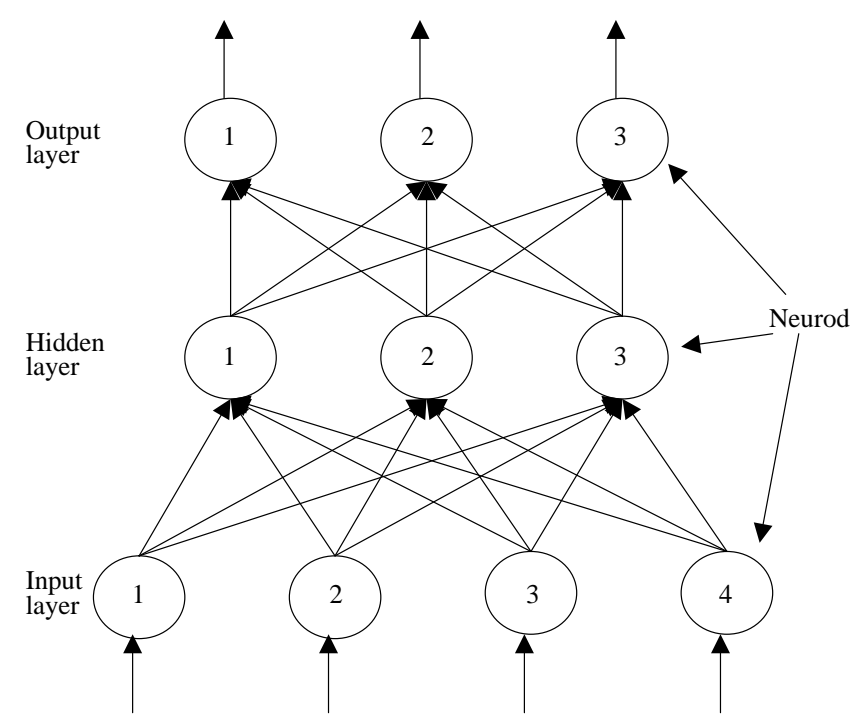

Fig. 1. Typical neural-network architecture. 
ence engine and defuzzification function systems in this paper. Figure 3 shows the structure of neuro-fuzzy system in this research, using Fuzzy C-Means (FCM) algorithm to extract the fuzzy rule and divide input patterns into similar clusters, and finds the prototype, $i$. e. cluster center. Each cluster in this system will map to a relative subnetwork, and the membership function is used to examine the degree of membership between each cluster and pattern. If the degree of membership is over the threshold, then the subnetwork will be fired. If there were many different subnetworks actived at the same time, all of the actived subnetworks were fired. Finally, we use the weighted average method to defuzzy, and use hyperbolic tangent function to transfer output value between -1 to 1 .

\section{Fuzzy rule}

The fuzzy rule can be presented by Equation (1)

$$
\begin{aligned}
& \text { IF } x_{j} \text { is } v_{1} \text { THEN } y=N N_{1} \\
& \text { IF } x_{j} \text { is } v_{2} \text { THEN } y=N N_{2} \\
& \text { IF } x_{j} \text { is } v_{c} \text { THEN } y=N N_{c}
\end{aligned}
$$

where $x_{j}$ is input vector, $x_{j}=\left[x_{j}^{1}, x_{j}^{2}, \cdots, x_{j}^{n}\right], v_{c}$ is the prototype of cluster $c, v_{c}=\left[v_{c}^{1}, v_{c}^{2}, \cdots, v_{c}^{n}\right]$, and $N N_{c}$ is the neuro network relative to cluster $c$.

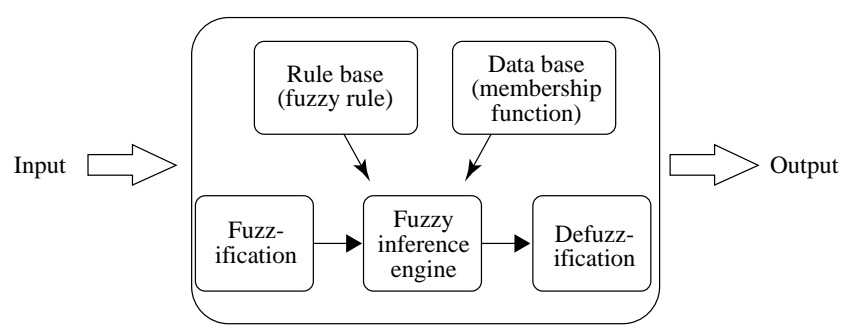

Fig. 2. Typical structure of fuzzy system.

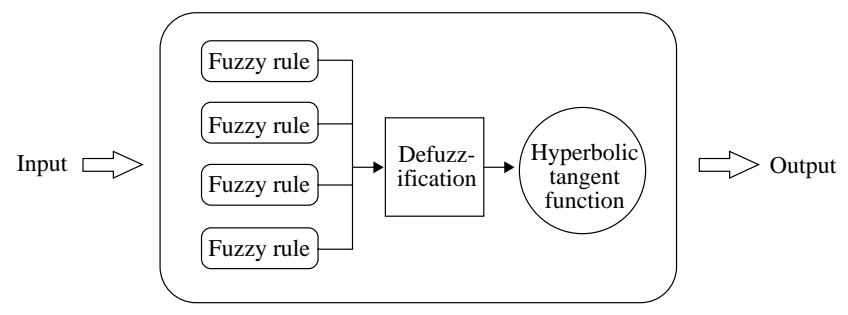

Fig. 3. Structure of neuro-fuzzy system.

\section{Determine the cluster center and membership matrix}

The FCM algorithm determines the cluster center and membership matrix $U$ using the following steps [14]:

Step 1 Initialized the membership matrix $U$ with a random values between 0 and 1 such that constraints in Equations (3) to (5) are satisfied.

$$
\begin{aligned}
& U=\left[u_{i j}\right]_{i=1}, \ldots, c ; j=1, \ldots, n \\
& \sum_{i=1}^{c} u_{i j}=1, \text { for } j=1,2, \ldots, n . \\
& 0<\sum_{j=1}^{n} u_{i j}<n, \text { for } i=1,2, \ldots, c . \\
& u_{i j} \in[0,1], \text { for } i=1, \ldots, c ; j=1, \ldots, n .
\end{aligned}
$$

where $c, i$ are number of cluster, $n, j$ are number of element, and $u_{i j}$ is degree of membership, between element $x_{j}$ and cluster $i$.

Step 2 Calculate the fuzzy cluster center

$$
v_{i}=\frac{1}{\sum_{j=1}^{n}\left(u_{i j}\right)^{m}} \sum_{j=1}^{n}\left(u_{i j}\right)^{m} x_{j} \text {, for } i=1,2, \ldots, c .
$$

where the $v_{i}$ is the cluster center, $x_{j}$, input vector.

Step 3 Calculate the objective function according Equation (6). Stop the iteration if its improvement over previous iteration is small than a certain threshold or a certain tolerance value

$$
J\left(u_{i j}, v_{i}\right)=\sum_{i=1}^{c} \sum_{j=1}^{n}\left(u_{i j}\right)^{m}\left\|x_{k}-v_{i}\right\|^{2}
$$

where $m \in[1, \infty]$ is a weight exponential, $v_{i}$ is the cluster center. $\|\bullet\|$ is Euclidean metric.

Step 4 Compute a new membership function $U$. Go to Step 2

$$
u_{i j}=\frac{1}{\sum_{k=1}^{c}\left(\left\|x_{j}-v_{i}\right\|^{2} /\left\|x_{j}-v_{k}\right\|^{2}\right)^{\frac{1}{m-1}}},
$$

for $i=1,2, \ldots, c ; j=1,2, \ldots, n$.

In this research we use the FCM function in the fuzzy logic toolbox of Matlab.

\section{Defuzzification}

After clustering procedure, the input vectors divide into different subnetworks. As shown in Figure 4, the subnetwork contains one hidden layer, a logic function works here as an activation function. Using a defuz- 
zification process, a fuzzy system transfers the input (fuzzy set) to a crisp output value. The defuz-zification uses the following steps:

Step 1 Calculate the fired value of neurons at hidden layer, and outputs of neurons in hidden layer.

$$
\begin{aligned}
& v_{j}(n)=w_{j i}(n) x_{i}(n) \\
& y_{j}(n)=f_{j}\left(v_{j}(n)\right)=\frac{1}{1+\exp \left(-v_{j}(n)\right)}
\end{aligned}
$$

where $v_{j}$ is fired value of neurons in hidden layer, $w_{j i}$ is the weight between input layer and hidden layer, $x_{i}$ is output of input layer, $y_{j}$ is output of neuron, and $f_{j}($.$) is$ a logic function.

Step 2 Calculate the fired value of neurons at output layer, and outputs of neurons in output layer.

$$
\begin{aligned}
& v_{k}(n)=w_{k j}(n) y_{j}(n) \\
& y_{k}(n)=f_{k}\left(v_{k}(n)\right)=v_{k}(n)
\end{aligned}
$$

where $v_{k}$ is fired value of neurons in output layer, $w_{k j}$ is the weight between output layer and hidden layer, and $y_{k}$ is output value of the output layer, and $f_{k}(\bullet)$ is linear activation function

Step 3 In the output layer, use the weighted average method to together those output value from all subnetwork.

$$
\hat{v}(n)=\frac{\sum_{p=1}^{c} m_{p} \cdot y_{k p}(n)}{\sum_{p=1}^{c} m_{p}}
$$

where $\hat{v}(n)$ is the defuzzification value in the output layer, $p$ is $P_{\text {th }}$ fuzzy rule, $c$ is the total number of fuzzy rule, $y_{k p}$ is output value of the $P_{\text {th }}$ fuzzy rule, and $m_{p}$ is the degree of membership that is greater than the vigilance value of $P_{\text {th }}$ fuzzy rule.

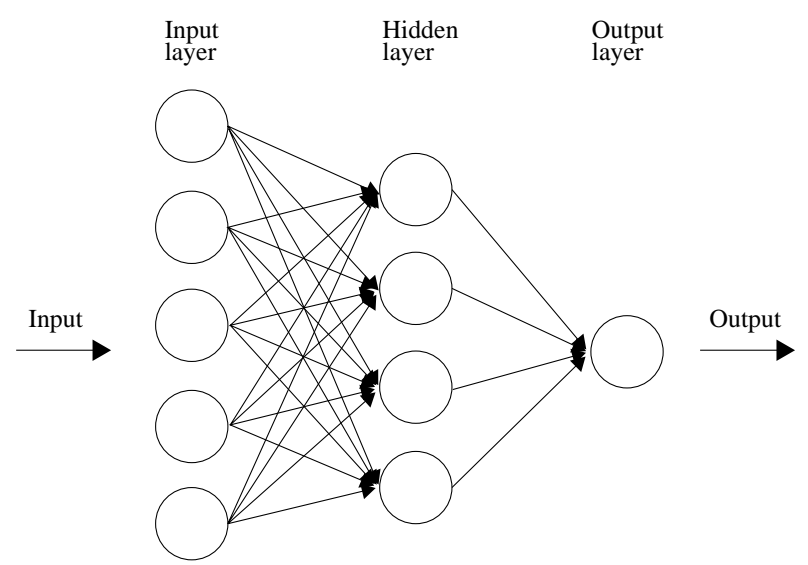

Fig. 4. Structure of subnetwork.
Step 4 Use hyperbolic tangent function transfers output value between -1 to 1 .

$$
\hat{y}(n)=\hat{f}(\hat{v}(n))=\frac{\exp (\hat{v}(n))-\exp (-\hat{v}(n))}{\exp (\hat{v}(n))+\exp (-\hat{v}(n))}
$$

where $\hat{f}(\cdot)$ is the hyperbolic tangent function.

\section{Learning in subnetwork}

Each subnetwork learns with a least-mean-squared (LSM) method or delta rule, in this paper the weights are updated to minimize the mean-squared error between the actual output and the desired output, the objective function is:

$$
E(n)=\frac{1}{2}[y(n)-\hat{y}(n)]^{2}
$$

where $y$ is the desired output, $\hat{y}$ is the network output signal.

The learning algorithm is described in the following steps:

Step 1. Initialized the weights with small random values. Step 2. Update the weight in output layer of subnetwork.

$$
\begin{aligned}
\Delta w_{k j}(n) & =-\eta \cdot \frac{\partial E(n)}{\partial w_{k j}(n)} \\
& =-\eta \cdot \frac{\partial E(n)}{\partial \hat{y}(n)} \cdot \frac{\partial \hat{y}(n)}{\partial \hat{v}(n)} \cdot \frac{\partial \hat{v}(n)}{\partial y_{k}(n)} \cdot \frac{\partial y_{k}(n)}{\partial v_{k}(n)} \cdot \frac{\partial v_{k}(n)}{\partial w_{k j}(n)} \\
& \left.=-\eta \cdot[-(y(n)-\bar{y}(n))] \cdot\left(1-\hat{y}^{2}\right)\right) \cdot \frac{m_{p}}{m_{1}+m_{2}+\cdots m_{c}} \\
& \cdot 1 \cdot y_{j}(n)
\end{aligned}
$$

where $\eta$ is learning parameter, $n$ is iterative number, $m_{p}$ is the degree of membership that is greater than the vigilance value of the $p_{t h}$ fuzzy rule, $c$ is the total number of fuzzy rule, $y_{j}$ is output value of the hidden layer of subnetwork.

Step 3. The weight update of subnetwork hidden layer

$$
\begin{aligned}
\Delta w_{j i}(n) & =-\eta \cdot \frac{\partial E(n)}{\partial w_{j i}(n)} \\
& =-\eta \cdot \frac{\partial E(n)}{\partial \hat{y}(n)} \cdot \frac{\partial \hat{y}(n)}{\partial \hat{v}(n)} \cdot \frac{\partial \hat{v}(n)}{\partial y_{k}(n)} \cdot \frac{\partial y_{k}(n)}{\partial v_{k}(n)} \cdot \frac{\partial v_{k}(n)}{\partial y_{j}(n)} \\
& \cdot \frac{\partial y_{j}(n)}{\partial v_{j}(n)} \cdot \frac{\partial v_{j}(n)}{\partial w_{j i}(n)} \\
& =-\eta \cdot[-(y(n)-\hat{y}(n))] \cdot\left(1-\bar{y}^{2}(n)\right) \\
& \cdot \frac{m_{p}}{m_{1}+m_{2}+\cdots m_{c}} \cdot 1 \cdot w_{k j}(n) \cdot\left[y_{j}(n)\right.
\end{aligned}
$$




$$
\left.\cdot\left(1-y_{j}(n)\right)\right] \cdot x_{i}(n)
$$

where $w_{k j}$ is the weight between output layer and hidden layer, and $x_{j}$ is input value of the subnetwork. In the back-propagation neural network we use a local gradient parameter $\delta$ to modify the weight.

$$
\begin{aligned}
& \Delta w_{k j}(n)=\eta \cdot \delta_{k}(n) \cdot y_{j}(n) \\
& \Delta w_{j i}(n)=\eta \cdot \delta_{j}(n) \cdot x_{i}(n) \\
& \delta_{k}(n)=[y(n)-\bar{y}(n)] \cdot\left(1-\hat{y}^{2}(n)\right) \cdot \frac{m_{p}}{m_{1}+m_{2}+\cdots m_{c}} \\
& \delta_{j}(n)=[y(n)-\bar{y}(n)] \cdot\left(1-\hat{y}^{2}(n)\right) \cdot \frac{m_{p}}{m_{1}+m_{2}+\cdots m_{c}} \\
& \bullet\left[y_{j}(n) \bullet\left(1-y_{j}(n)\right)\right] \\
& =d_{k}(n) \bullet w_{k l}(n) \bullet\left[y_{j}(n) \bullet\left(1-y_{j}(n)\right)\right]
\end{aligned}
$$

\section{OVERVIEW OF NDT}

\section{Categories of NDT equipment}

Nondestructive testing equipment for airport pavements can be broadly classified as nondeflection and deflection testing equipment [24]. Nondeflection measuring equipment includes ground-penetrating radar, infrared thermography, dynamic cone penetrometer, and devices that measure surface friction, roughness, and surface waves. Deflection measuring equipment can be broadly classified as static or dynamic loading devices. Static loading devices are such as Benkelman Beam and other types of plate bearing tests. Dynamic loading equipment can be further classified to vibratory and impulse devices. Steady-state vibratory devices are including Dynaflect and Road Rater. Impulse load devices are such as the FWD or Heavy- Falling Weight Deflectometer (HWD). The manufacturers including KUAB America, Dynatest Group, Phoenix Scientific Inc., Foundation Mechanics Inc., and Viatest. The impulse load devices are most popular and widely used in the world.

\section{Theory of heavy-falling weight deflectometer}

Early use of deflection data typically involved consideration of maximum deflection directly under the load, relative to experimental standards. Usually some statistical measure of deflections on a pavement section is compared with an "allowable" deflection level for that section under the expected traffic.
The HWD equipment measures pavement surface deflections from an applied dynamic load that simulates a moving wheel, pavement deflections are recorded directly beneath the load plate and the outermost sensor provides an indication of subgrade strength data. The moduli derived in this way are considered representative of the pavement response to load, and can be used to calculate stresses or strains in the pavement structure for analysis purposes. Calculations of theoretical deflections, and the subsequent stress or strain calculations, currently typically involve linear elastic theory. Empirical use of deflection basin data usually involves one of the "basin parameters" which combine some or all of the measured basin deflections into a single number. use of:

Application of elastic theory may be through the

1. Traditional layered elastic programs based on numerical integration procedures such as ELSYM5, CHEVRON (various versions), BISAR and WESLEA.

2. The Odemark-Boussinesq transformed section approach rather than numerical integration.

3. Finite element programs, either those that have been specifically oriented towards pavement analysis, such as ILLI-PAVE or MICHPAVE, or general structural analysis programs such as SAP (various versions), ANSYS, ABACUS, ADINA, etc.

4. Plate theory such as the Westergaard solutions for PCC pavements.

\section{Impulse stiffness modulus}

Pavement stiffness is defined as the dynamic force divided by the pavement deflection at the center of the load plate.

$$
I(D) S M=\frac{L}{d_{o}}
$$

Where $I(D) S M$ is impulse (dynamic) stiffness modulus (kips/inch), $L$ is applied load (kips) and $d_{0}$ is maximum deflection of load plate (inches).

\section{Back-calculation}

Structural evaluation of pavement deflection response using Non-Destructive Test (NDT) data has been growing since the introduction of the Benkelman Beam at the WASHO Road Test in the early 1950's. Developments in analytical techniques, coupled with improved deflection measurement capabilities, have resulted in the current so-called back-calculation techniques widely employed in pavement evaluation $[9,24]$.

Briefly, the back-calculation procedure involves calculation of theoretical deflections under the applied 
load using assumed pavement layer modulus. These theoretical deflections are compared with measured deflections and the assumed modulus are then adjusted in an intricate procedure until theoretical and measured deflection basins match acceptably well.

Since empirical rules are difficult to generalize across a wide range of pavement types, loading and local environmental conditions, newly developed software tend to reduce the reliance on empirical approaches. Instead, pavements can be analyzed like most other civil engineering structures, i.e., through the use of calculated and allowable stresses and strains at critical points within the pavement structure, under load. The relationships between allowable stresses and strains, and pavement distress, remain essentially empirical. The calculation of existing stresses and strains within the pavement structure can be accomplished through an analytical or mechanistic approach.

\section{PCC joints analysis}

It is very important to analyze the load transfer efficiency between adjacent PCC slab joints, because the load transfer efficiency can significantly impact the structural capacity of the pavement. In this paper equation has been adopted to define deflection load transfer efficiency.

$$
L T E_{\Delta}=\left(\frac{\Delta_{\text {unloaded_slab }}}{\Delta_{\text {loaded_slab }}}\right) 100 \%
$$

Where $L T E_{\Delta}$ is deflection load transfer efficiency (percent), $\Delta_{\text {loaded_slab }}$ is deflection on loaded slab normally under load plate (mils), and $\Delta_{\text {unloaded_slab }}$ is deflection on adjacent unloaded slab (mils).

\section{CASE STUDIES}

In this research, HWD test data were collected using the equipment made by Dynatest Group, and a back-calculation program Elmod 4.5 was adopted for data analysis. Total 331 records combined HWD test and PCI investigation were used in the case study, 280 of these case records are used for the training case, and 51 for the testing phase. Details are shown in Table 1 and 2, respectively, input parameters include layer thickness of PCC, thickness of subbase, ISM, $E$ modulus of PCC, $E$ modulus of subbase, $E$ modulus of subgrade, subgrade reaction at center, subgrade reaction at corner, joint load transfer, and pavement surface condition. As shown in Table 3, there are 12 types of pavement surface distress, in this research we set the input value equal 1 when the pavement surface exists any surface distress.
A hyperbolic tangent function transfers output value between -1 to 1 , the value -1 means the pavement condition is well, and value 1 means the pavement slab has some problem about cracks, distress of joint, or distress of surface.

The results of the predications using this neurofuzzy system would have been tabulated in Table 1 and 2 alongside the actual field performance, the training rate and learning curve are shown in Figures 5 and 6 individually. There are 28 errors in the training data and 16 errors in testing data $(90 \%$ success rate in training and $68.6 \%$ success rate in testing, overall $86.7 \%$, as shown at Table 4). This indicates that the present neurofuzzy system with the ability for evaluating pavement failure potential.

\section{CONCLUSION}

For developing a pavement maintenance and rehabilitation strategy, the correlation between structural and functional performances is important. For example, due to environmental distress, a pavement may have a low PCI value, but it still has sufficient strength to accommodate structural loading.

In this research a neuro-fuzzy system network has been used to model the complex relationship between rigid pavement, subbase, subgrade, joint load transfer, and in-situ condition, and $90 \%$ success rate in training and $68.6 \%$ success rate in testing, overall $86.7 \%$. In the Table 4 we find the error rate of "predicting to damage but actually not" significant increase in testing phase, but the locations are random distributed in the airport area, as shown in Figure 7. In this research, we have 10 input parameters but only have 240 training records, it seems that in the future research needs more training

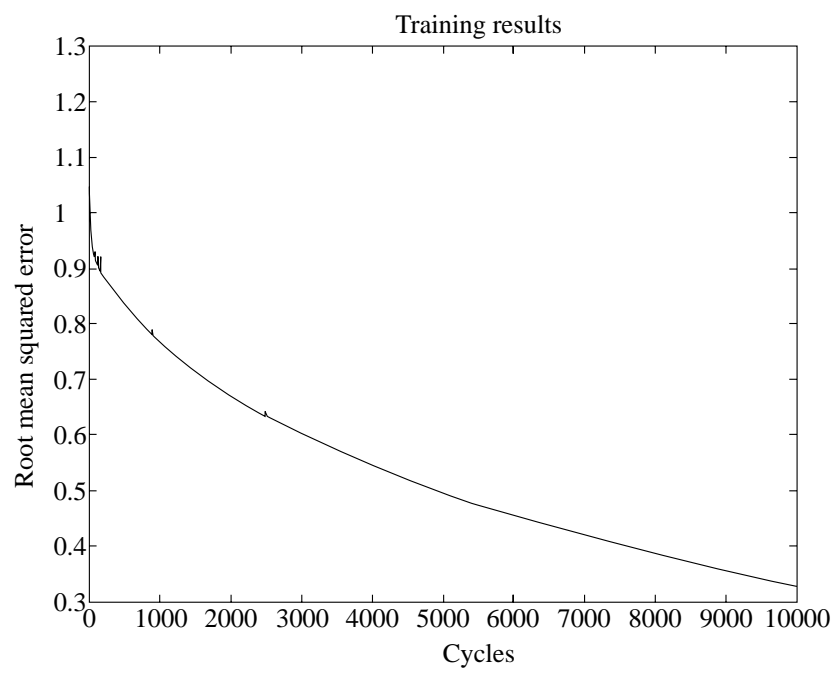

Fig. 5. Learning curve of neuro-fuzzy system. 
Table 1. Field behavior data for training set

(1: damage, -1: no damage) The shadow determinates the error of prediction

\begin{tabular}{|c|c|c|c|c|c|c|c|c|c|c|c|}
\hline \multirow[t]{2}{*}{ No. } & \multicolumn{2}{|c|}{$\begin{array}{l}\text { Layer } \\
\text { thickness } \\
(\mathrm{mm})\end{array}$} & \multirow{2}{*}{$\begin{array}{c}\mathrm{ISM} \\
(\mathrm{kN} / \mathrm{mm})\end{array}$} & \multicolumn{3}{|c|}{ E modulus (Mpa) } & \multicolumn{2}{|c|}{$\begin{array}{l}\text { Subgrade } \\
\text { reaction } \\
(\mathrm{kPa} / \mathrm{mm})\end{array}$} & \multirow{2}{*}{$\begin{array}{c}\begin{array}{c}\text { Load } \\
\text { transfer }\end{array} \\
(\%)\end{array}$} & \multirow[t]{2}{*}{$\begin{array}{c}\text { Field } \\
\text { behavior }\end{array}$} & \multirow[t]{2}{*}{$\begin{array}{l}\text { Trainning } \\
\text { result }\end{array}$} \\
\hline & PCC & Subbase & & Concrete & Subbase & Subgrade & $\mathrm{kc}$ & $\mathrm{kj}$ & & & \\
\hline 1 & 380 & 200 & 930 & 18356 & 949 & 427 & 91 & 168 & 98.4 & 1 & 0.775 \\
\hline 2 & 380 & 200 & 1251 & 34746 & 565 & 473 & 77 & 73 & 27.2 & 1 & 0.767 \\
\hline 3 & 380 & 200 & 1042 & 32600 & 451 & 329 & 77 & 78 & 28.0 & 1 & 0.762 \\
\hline 4 & 380 & 200 & 1160 & 48381 & 779 & 323 & 64 & 52 & 54.8 & 1 & 0.909 \\
\hline 5 & 380 & 200 & 921 & 29700 & 566 & 257 & 64 & 42 & 17.3 & -1 & -0.576 \\
\hline 6 & 410 & 200 & 1227 & 32588 & 456 & 354 & 87 & 42 & 88.5 & 1 & 0.192 \\
\hline 7 & 380 & 200 & 1104 & 32496 & 595 & 327 & 84 & 43 & 70.9 & 1 & -0.223 \\
\hline 8 & 380 & 200 & 1222 & 30825 & 604 & 547 & 108 & 117 & 51.9 & 1 & 0.843 \\
\hline 9 & 380 & 200 & 888 & 19863 & 935 & 370 & 66 & 61 & 68.5 & 1 & 0.298 \\
\hline 10 & 380 & 200 & 922 & 25093 & 1182 & 213 & 67 & 28 & 5.8 & 1 & 0.661 \\
\hline 11 & 380 & 200 & 834 & 23063 & 722 & 244 & 63 & 45 & 25.1 & 1 & 0.319 \\
\hline 12 & 380 & 200 & 1021 & 31155 & 563 & 307 & 75 & 14 & 51.6 & -1 & -0.861 \\
\hline 13 & 380 & 200 & 990 & 32353 & 420 & 278 & 69 & 44 & 15.7 & 1 & 0.661 \\
\hline 14 & 380 & 200 & 1126 & 38278 & 592 & 382 & 76 & 89 & 95.3 & 1 & 0.681 \\
\hline 15 & 380 & 200 & 1126 & 29003 & 629 & 410 & 100 & 100 & 95.6 & 1 & 0.716 \\
\hline 16 & 380 & 200 & 1123 & 29751 & 502 & 410 & 95 & 82 & 95.5 & 1 & 0.889 \\
\hline 17 & 410 & 200 & 1339 & 31613 & 620 & 436 & 103 & 26 & 69.6 & -1 & -0.601 \\
\hline 18 & 410 & 200 & 1061 & 30366 & 376 & 333 & 71 & 117 & 98.6 & -1 & 0.057 \\
\hline 19 & 410 & 200 & 1007 & 27064 & 388 & 341 & 71 & 133 & 97.4 & -1 & -0.309 \\
\hline 20 & 410 & 200 & 932 & 22367 & 472 & 334 & 70 & 85 & 97.2 & 1 & 0.644 \\
\hline 21 & 380 & 200 & 956 & 33081 & 359 & 333 & 66 & 45 & 85.7 & -1 & -0.986 \\
\hline 22 & 380 & 200 & 1090 & 35734 & 578 & 261 & 76 & 45 & 85.9 & 1 & 0.208 \\
\hline 23 & 380 & 200 & 1149 & 35597 & 550 & 328 & 85 & 81 & 73.4 & 1 & -0.843 \\
\hline 24 & 380 & 200 & 1021 & 29378 & 517 & 381 & 80 & 75 & 93.9 & 1 & -0.290 \\
\hline 25 & 380 & 200 & 1032 & 32372 & 564 & 298 & 74 & 86 & 91.5 & 1 & 0.875 \\
\hline 26 & 380 & 200 & 1099 & 33575 & 578 & 324 & 81 & 105 & 97.8 & 1 & -0.772 \\
\hline 27 & 380 & 200 & 1098 & 33256 & 483 & 319 & 84 & 108 & 91.3 & 1 & -0.172 \\
\hline 28 & 380 & 200 & 1021 & 31747 & 461 & 293 & 76 & 120 & 96.8 & 1 & 0.019 \\
\hline 29 & 380 & 200 & 928 & 31008 & 732 & 237 & 60 & 119 & 97.6 & -1 & -0.957 \\
\hline 30 & 380 & 200 & 1026 & 31087 & 431 & 293 & 78 & 140 & 97.8 & 1 & 0.120 \\
\hline 31 & 380 & 200 & 976 & 31485 & 608 & 273 & 67 & 123 & 95.1 & 1 & -0.586 \\
\hline 32 & 380 & 200 & 1005 & 34808 & 395 & 284 & 69 & 127 & 96.6 & -1 & -0.851 \\
\hline 33 & 380 & 200 & 906 & 33266 & 376 & 242 & 59 & 77 & 97.5 & -1 & -0.963 \\
\hline 34 & 380 & 200 & 1067 & 33945 & 405 & 285 & 79 & 58 & 87.3 & -1 & -0.671 \\
\hline 35 & 380 & 200 & 1105 & 32008 & 550 & 317 & 86 & 127 & 94.1 & -1 & -0.864 \\
\hline 36 & 380 & 200 & 1167 & 34509 & 485 & 293 & 91 & 138 & 89.7 & -1 & -0.860 \\
\hline 37 & 380 & 200 & 1237 & 36383 & 557 & 441 & 96 & 99 & 91.8 & 1 & 0.367 \\
\hline 38 & 380 & 200 & 1293 & 33714 & 569 & 483 & 112 & 91 & 84.0 & -1 & -0.848 \\
\hline 39 & 380 & 200 & 1288 & 30382 & 728 & 596 & 118 & 118 & 81.4 & 1 & 0.897 \\
\hline 40 & 380 & 200 & 1333 & 42353 & 565 & 462 & 98 & 110 & 91.2 & -1 & -0.727 \\
\hline 41 & 410 & 200 & 1464 & 32373 & 381 & 669 & 127 & 166 & 93.6 & 1 & 0.956 \\
\hline 42 & 410 & 200 & 1278 & 29247 & 718 & 370 & 99 & 63 & 88.2 & -1 & -0.829 \\
\hline 43 & 410 & 200 & 1058 & 25823 & 658 & 309 & 76 & 92 & 92.4 & 1 & 0.075 \\
\hline 44 & 380 & 200 & 1089 & 31388 & 615 & 258 & 84 & 84 & 87.6 & 1 & 0.608 \\
\hline 45 & 380 & 200 & 1103 & 29790 & 608 & 328 & 90 & 120 & 96.5 & -1 & -0.972 \\
\hline 46 & 380 & 200 & 1063 & 28768 & 752 & 288 & 84 & 86 & 78.6 & 1 & -0.469 \\
\hline 47 & 380 & 200 & 924 & 26413 & 723 & 234 & 69 & 67 & 93.1 & -1 & -0.670 \\
\hline 48 & 380 & 200 & 1046 & 28161 & 743 & 363 & 83 & 117 & 88.7 & -1 & -0.731 \\
\hline 49 & 380 & 200 & 1050 & 29069 & 819 & 312 & 80 & 97 & 93.3 & -1 & -0.914 \\
\hline 50 & 380 & 200 & 1181 & 28419 & 713 & 528 & 105 & 79 & 84.3 & 1 & 0.757 \\
\hline 51 & 380 & 200 & 1126 & 36564 & 873 & 289 & 75 & 84 & 92.5 & 1 & 0.768 \\
\hline
\end{tabular}


Table 1. Field behavior data for training set (continued)

(1: damage, -1: no damage) The shadow determinates the error of prediction

\begin{tabular}{|c|c|c|c|c|c|c|c|c|c|c|c|}
\hline \multirow[t]{2}{*}{ No. } & \multicolumn{2}{|c|}{$\begin{array}{l}\text { Layer } \\
\text { thickness } \\
(\mathrm{mm})\end{array}$} & \multirow{2}{*}{$\begin{array}{c}\text { ISM } \\
(\mathrm{kN} / \mathrm{mm})\end{array}$} & \multicolumn{3}{|c|}{ E modulus (Mpa) } & \multicolumn{2}{|c|}{$\begin{array}{l}\text { Subgrade } \\
\text { reaction } \\
(\mathrm{kPa} / \mathrm{mm})\end{array}$} & \multirow{2}{*}{$\begin{array}{l}\text { Load } \\
\text { transfer } \\
(\%)\end{array}$} & \multirow[t]{2}{*}{$\begin{array}{c}\text { Field } \\
\text { behavior }\end{array}$} & \multirow[t]{2}{*}{$\begin{array}{l}\text { Trainning } \\
\text { result }\end{array}$} \\
\hline & PCC & Subbase & & Concrete & Subbase & Subgrade & $\mathrm{kc}$ & $\mathrm{kj}$ & & & \\
\hline 52 & 410 & 200 & 1218 & 21716 & 573 & 574 & 119 & 143 & 95.1 & -1 & -0.744 \\
\hline 53 & 410 & 200 & 1461 & 34639 & 780 & 436 & 110 & 84 & 91.0 & 1 & 0.705 \\
\hline 54 & 410 & 200 & 1306 & 30603 & 805 & 399 & 98 & 38 & 97.9 & -1 & -0.922 \\
\hline 55 & 410 & 200 & 1236 & 30407 & 868 & 369 & 87 & 71 & 80.8 & -1 & -0.841 \\
\hline 56 & 410 & 200 & 1353 & 35762 & 674 & 367 & 94 & 80 & 90.8 & -1 & -0.952 \\
\hline 57 & 410 & 200 & 1109 & 34168 & 274 & 277 & 72 & 105 & 82.4 & -1 & -0.730 \\
\hline 58 & 410 & 200 & 1259 & 30823 & 648 & 438 & 93 & 130 & 95.8 & -1 & -0.924 \\
\hline 59 & 380 & 200 & 1227 & 33487 & 495 & 468 & 103 & 88 & 76.8 & -1 & -0.796 \\
\hline 60 & 380 & 200 & 809 & 30005 & 329 & 225 & 52 & 84 & 84.4 & -1 & -0.992 \\
\hline 61 & 380 & 200 & 996 & 35195 & 500 & 265 & 65 & 60 & 59.2 & -1 & -0.918 \\
\hline 62 & 380 & 200 & 896 & 26661 & 410 & 219 & 69 & 64 & 52.4 & -1 & -0.665 \\
\hline 63 & 380 & 200 & 941 & 30297 & 405 & 314 & 68 & 83 & 89.3 & -1 & -0.949 \\
\hline 64 & 380 & 200 & 996 & 32492 & 422 & 259 & 71 & 85 & 81.3 & -1 & -0.965 \\
\hline 65 & 380 & 200 & 1289 & 39048 & 488 & 350 & 100 & 111 & 50.1 & -1 & -0.868 \\
\hline 66 & 410 & 200 & 1042 & 36614 & 438 & 223 & 57 & 51 & 58.2 & 1 & 0.716 \\
\hline 67 & 410 & 200 & 939 & 28729 & 352 & 209 & 53 & 184 & 43.2 & 1 & 0.788 \\
\hline 68 & 410 & 200 & 974 & 38793 & 417 & 175 & 48 & 73 & 84.6 & 1 & 0.577 \\
\hline 69 & 410 & 200 & 852 & 33868 & 406 & 202 & 41 & 32 & 25.1 & 1 & 0.366 \\
\hline 70 & 410 & 200 & 965 & 40650 & 463 & 198 & 44 & 5 & 42.5 & 1 & 0.677 \\
\hline 71 & 410 & 200 & 925 & 35815 & 543 & 183 & 45 & 64 & 55.4 & 1 & 0.797 \\
\hline 72 & 410 & 200 & 772 & 26966 & 382 & 169 & 42 & 59 & 31.9 & 1 & 0.606 \\
\hline 73 & 410 & 200 & 744 & 29352 & 446 & 192 & 36 & 22 & 73.1 & -1 & -0.829 \\
\hline 74 & 410 & 200 & 1081 & 43688 & 380 & 196 & 53 & 100 & 93.2 & -1 & -0.859 \\
\hline 75 & 410 & 200 & 1081 & 43688 & 380 & 196 & 53 & 100 & 93.2 & -1 & -0.859 \\
\hline 76 & 410 & 200 & 1151 & 24455 & 668 & 504 & 95 & 90 & 97.3 & -1 & -0.908 \\
\hline 77 & 380 & 200 & 804 & 31370 & 589 & 176 & 46 & 74 & 97.7 & -1 & -0.997 \\
\hline 78 & 380 & 200 & 1011 & 31907 & 817 & 264 & 66 & 100 & 97.4 & -1 & -0.903 \\
\hline 79 & 380 & 200 & 983 & 28922 & 577 & 287 & 74 & 113 & 97.7 & -1 & -0.759 \\
\hline 80 & 380 & 200 & 1056 & 28716 & 675 & 295 & 84 & 123 & 98.0 & -1 & -0.922 \\
\hline 81 & 380 & 200 & 1024 & 30975 & 607 & 256 & 75 & 84 & 98.9 & -1 & -0.264 \\
\hline 82 & 380 & 200 & 1119 & 33629 & 761 & 381 & 81 & 102 & 98.0 & -1 & -0.928 \\
\hline 83 & 380 & 200 & 978 & 26966 & 592 & 299 & 78 & 99 & 96.4 & -1 & -0.753 \\
\hline 84 & 410 & 200 & 1192 & 29433 & 796 & 326 & 85 & 95 & 95.2 & -1 & -0.997 \\
\hline 85 & 410 & 200 & 1098 & 23523 & 868 & 403 & 86 & 136 & 95.3 & -1 & -0.823 \\
\hline 86 & 410 & 200 & 1090 & 24787 & 505 & 466 & 87 & 114 & 98.8 & -1 & -0.684 \\
\hline 87 & 380 & 200 & 1236 & 43251 & 607 & 401 & 82 & 117 & 97.4 & 1 & 0.820 \\
\hline 88 & 380 & 200 & 1135 & 30702 & 705 & 417 & 91 & 140 & 98.8 & 1 & 0.112 \\
\hline 89 & 380 & 200 & 1077 & 37730 & 426 & 314 & 73 & 107 & 99.3 & -1 & -0.743 \\
\hline 90 & 380 & 200 & 945 & 34203 & 495 & 246 & 60 & 61 & 94.3 & -1 & -0.952 \\
\hline 91 & 380 & 200 & 1028 & 33507 & 525 & 294 & 72 & 86 & 99.8 & -1 & -0.815 \\
\hline 92 & 380 & 200 & 985 & 26360 & 597 & 360 & 80 & 65 & 97.3 & -1 & -0.870 \\
\hline 93 & 380 & 200 & 1017 & 27859 & 531 & 418 & 83 & 105 & 99.4 & -1 & -0.836 \\
\hline 94 & 380 & 200 & 917 & 30731 & 507 & 242 & 62 & 115 & 97.9 & -1 & -0.931 \\
\hline 95 & 380 & 200 & 979 & 33815 & 415 & 258 & 67 & 106 & 97.1 & -1 & -0.926 \\
\hline 96 & 380 & 200 & 942 & 29055 & 482 & 265 & 69 & 89 & 69.9 & -1 & -0.949 \\
\hline 97 & 380 & 200 & 1130 & 31965 & 654 & 321 & 88 & 157 & 98.2 & -1 & -0.917 \\
\hline 98 & 380 & 200 & 1136 & 33988 & 578 & 309 & 86 & 81 & 73.4 & -1 & -0.620 \\
\hline 99 & 380 & 200 & 1010 & 32836 & 455 & 260 & 72 & 84 & 94.1 & 1 & -0.689 \\
\hline 100 & 380 & 200 & 1233 & 34296 & 579 & 445 & 100 & 117 & 70.3 & -1 & -0.652 \\
\hline 101 & 380 & 200 & 1121 & 36533 & 573 & 331 & 79 & 77 & 95.3 & -1 & 0.142 \\
\hline 102 & 380 & 200 & 1414 & 41055 & 416 & 511 & 116 & 201 & 94.6 & 1 & 0.928 \\
\hline
\end{tabular}


Table 1. Field behavior data for training set (continued)

(1: damage, -1 : no damage) The shadow determinates the error of prediction

\begin{tabular}{|c|c|c|c|c|c|c|c|c|c|c|c|}
\hline \multirow[t]{2}{*}{ No. } & \multicolumn{2}{|c|}{$\begin{array}{l}\text { Layer } \\
\text { thickness } \\
(\mathrm{mm})\end{array}$} & \multirow{2}{*}{$\begin{array}{c}\text { ISM } \\
(\mathrm{kN} / \mathrm{mm})\end{array}$} & \multicolumn{3}{|c|}{ E modulus (Mpa) } & \multicolumn{2}{|c|}{$\begin{array}{l}\text { Subgrade } \\
\text { reaction } \\
(\mathrm{kPa} / \mathrm{mm})\end{array}$} & \multirow{2}{*}{$\begin{array}{c}\begin{array}{c}\text { Load } \\
\text { transfer }\end{array} \\
(\%)\end{array}$} & \multirow[t]{2}{*}{$\begin{array}{c}\text { Field } \\
\text { behavior }\end{array}$} & \multirow[t]{2}{*}{$\begin{array}{l}\text { Trainning } \\
\text { result }\end{array}$} \\
\hline & PCC & Subbase & & Concrete & Subbase & Subgrade & $\mathrm{kc}$ & $\mathrm{kj}$ & & & \\
\hline 103 & 410 & 200 & 1368 & 32977 & 541 & 434 & 105 & 166 & 97.9 & 1 & -0.133 \\
\hline 104 & 410 & 200 & 1022 & 29894 & 304 & 270 & 68 & 68 & 17.2 & 1 & -0.069 \\
\hline 105 & 410 & 200 & 1167 & 35244 & 376 & 387 & 75 & 57 & 80.6 & -1 & -0.162 \\
\hline 106 & 380 & 200 & 1067 & 47404 & 234 & 328 & 62 & 42 & 84.6 & -1 & -0.940 \\
\hline 107 & 380 & 200 & 1140 & 38046 & 268 & 372 & 85 & 76 & 31.3 & -1 & -0.663 \\
\hline 108 & 380 & 200 & 947 & 34721 & 255 & 312 & 64 & 58 & 27.2 & -1 & -0.310 \\
\hline 109 & 380 & 200 & 957 & 39439 & 237 & 248 & 59 & 49 & 25.2 & -1 & -0.463 \\
\hline 110 & 380 & 200 & 1080 & 41107 & 255 & 290 & 71 & 67 & 24.9 & 1 & 0.326 \\
\hline 111 & 380 & 200 & 1156 & 41124 & 373 & 319 & 79 & 58 & 23.4 & -1 & -0.403 \\
\hline 112 & 380 & 200 & 752 & 28611 & 188 & 186 & 49 & 50 & 11.2 & -1 & -0.963 \\
\hline 113 & 380 & 200 & 1065 & 33511 & 287 & 429 & 82 & 60 & 53.4 & 1 & 0.993 \\
\hline 114 & 380 & 200 & 1002 & 36942 & 331 & 326 & 66 & 62 & 22.1 & 1 & 0.502 \\
\hline 115 & 380 & 200 & 950 & 37611 & 219 & 255 & 61 & 56 & 21.4 & -1 & -0.611 \\
\hline 116 & 380 & 200 & 889 & 34544 & 450 & 215 & 54 & 38 & 19.3 & -1 & -0.818 \\
\hline 117 & 380 & 200 & 1245 & 42660 & 347 & 438 & 89 & 39 & 34.9 & 1 & 0.983 \\
\hline 118 & 380 & 200 & 1050 & 38722 & 297 & 323 & 70 & 46 & 14.3 & 1 & 0.249 \\
\hline 119 & 380 & 200 & 965 & 35437 & 231 & 304 & 66 & 47 & 17.3 & -1 & -0.433 \\
\hline 120 & 380 & 200 & 1133 & 40437 & 363 & 300 & 77 & 49 & 14.5 & -1 & -0.643 \\
\hline 121 & 380 & 200 & 1266 & 43401 & 439 & 452 & 89 & 45 & 39.9 & 1 & 0.613 \\
\hline 122 & 410 & 200 & 1278 & 42500 & 339 & 326 & 77 & 38 & 15.0 & -1 & -0.952 \\
\hline 123 & 410 & 200 & 1207 & 33324 & 288 & 474 & 87 & 64 & 95.7 & 1 & 0.960 \\
\hline 124 & 380 & 200 & 920 & 30691 & 325 & 312 & 66 & 24 & 48.4 & -1 & -0.609 \\
\hline 125 & 380 & 200 & 1025 & 36843 & 318 & 280 & 70 & 65 & 28.7 & 1 & -0.008 \\
\hline 126 & 380 & 200 & 932 & 37684 & 216 & 293 & 58 & 34 & 94.9 & -1 & -0.997 \\
\hline 127 & 380 & 200 & 901 & 34715 & 261 & 220 & 58 & 47 & 14.1 & -1 & -0.983 \\
\hline 128 & 380 & 200 & 1055 & 37160 & 363 & 284 & 72 & 78 & 22.5 & -1 & -0.061 \\
\hline 129 & 380 & 200 & 936 & 33771 & 237 & 225 & 95 & 25 & 57.3 & 1 & 0.849 \\
\hline 130 & 380 & 200 & 870 & 30704 & 327 & 238 & 59 & 48 & 76.6 & -1 & -0.871 \\
\hline 131 & 380 & 200 & 1000 & 35424 & 243 & 334 & 70 & 47 & 93.3 & -1 & -0.898 \\
\hline 132 & 380 & 200 & 1021 & 35934 & 319 & 290 & 71 & 80 & 96.2 & -1 & -0.958 \\
\hline 133 & 380 & 200 & 1171 & 42950 & 339 & 338 & 79 & 84 & 95.3 & 1 & 0.355 \\
\hline 134 & 410 & 200 & 1053 & 27463 & 381 & 316 & 76 & 86 & 97.7 & 1 & 0.283 \\
\hline 135 & 410 & 200 & 1137 & 33033 & 296 & 324 & 77 & 53 & 89.0 & -1 & -0.437 \\
\hline 136 & 380 & 200 & 1130 & 35264 & 455 & 312 & 85 & 43 & 96.0 & -1 & -0.565 \\
\hline 137 & 380 & 200 & 867 & 31903 & 532 & 241 & 54 & 61 & 85.0 & -1 & -0.995 \\
\hline 138 & 380 & 200 & 938 & 27991 & 543 & 255 & 70 & 73 & 40.7 & -1 & -0.790 \\
\hline 139 & 380 & 200 & 1021 & 30679 & 502 & 342 & 77 & 45 & 83.5 & 1 & 0.208 \\
\hline 140 & 380 & 200 & 470 & 14440 & 483 & 102 & 32 & 51 & 35.6 & -1 & -0.541 \\
\hline 141 & 380 & 200 & 923 & 27847 & 557 & 262 & 68 & 77 & 97.0 & 1 & -0.250 \\
\hline 142 & 380 & 200 & 1134 & 37279 & 557 & 308 & 79 & 43 & 59.8 & -1 & -0.909 \\
\hline 143 & 380 & 200 & 1046 & 34735 & 470 & 291 & 73 & 42 & 81.9 & -1 & -0.749 \\
\hline 144 & 380 & 200 & 1199 & 33865 & 925 & 361 & 90 & 120 & 94.5 & -1 & -0.894 \\
\hline 145 & 380 & 200 & 996 & 29542 & 281 & 404 & 81 & 67 & 99.1 & -1 & -0.616 \\
\hline 146 & 380 & 200 & 1252 & 39966 & 349 & 383 & 95 & 73 & 94.6 & -1 & -0.703 \\
\hline 147 & 380 & 200 & 969 & 23993 & 1114 & 282 & 77 & 77 & 20.4 & -1 & -0.723 \\
\hline 148 & 380 & 200 & 1076 & 36541 & 145 & 338 & 82 & 62 & 84.9 & 1 & 0.125 \\
\hline 149 & 380 & 200 & 898 & 38474 & 85 & 246 & 57 & 44 & 16.0 & -1 & -0.882 \\
\hline 150 & 410 & 200 & 1122 & 29785 & 659 & 353 & 76 & 99 & 96.0 & -1 & -0.967 \\
\hline 151 & 410 & 200 & 1102 & 28350 & 694 & 356 & 76 & 123 & 97.2 & -1 & -0.812 \\
\hline 152 & 410 & 200 & 1017 & 29949 & 272 & 342 & 68 & 97 & 91.9 & -1 & -0.682 \\
\hline 153 & 410 & 200 & 1510 & 32248 & 2201 & 534 & 108 & 105 & 88.5 & 1 & -0.318 \\
\hline
\end{tabular}


Table 1. Field behavior data for training set (continued)

(1: damage, -1: no damage) The shadow determinates the error of prediction

\begin{tabular}{|c|c|c|c|c|c|c|c|c|c|c|c|}
\hline \multirow[t]{2}{*}{ No. } & \multicolumn{2}{|c|}{$\begin{array}{l}\text { Layer } \\
\text { thickness } \\
(\mathrm{mm})\end{array}$} & \multirow{2}{*}{$\begin{array}{c}\text { ISM } \\
(\mathrm{kN} / \mathrm{mm})\end{array}$} & \multicolumn{3}{|c|}{ E modulus (Mpa) } & \multicolumn{2}{|c|}{$\begin{array}{l}\text { Subgrade } \\
\text { reaction } \\
(\mathrm{kPa} / \mathrm{mm})\end{array}$} & \multirow{2}{*}{$\begin{array}{c}\begin{array}{c}\text { Load } \\
\text { transfer }\end{array} \\
(\%)\end{array}$} & \multirow[t]{2}{*}{$\begin{array}{c}\text { Field } \\
\text { behavior }\end{array}$} & \multirow[t]{2}{*}{$\begin{array}{l}\text { Trainning } \\
\text { result }\end{array}$} \\
\hline & PCC & Subbase & & Concrete & Subbase & Subgrade & $\mathrm{kc}$ & $\mathrm{kj}$ & & & \\
\hline 154 & 410 & 200 & 1097 & 30673 & 743 & 296 & 70 & 95 & 96.8 & -1 & -0.924 \\
\hline 155 & 410 & 200 & 1017 & 29949 & 272 & 342 & 68 & 97 & 91.9 & -1 & -0.682 \\
\hline 156 & 410 & 200 & 1510 & 32248 & 2201 & 534 & 108 & 105 & 88.5 & -1 & -0.318 \\
\hline 157 & 410 & 200 & 1103 & 28733 & 424 & 392 & 80 & 137 & 98.9 & -1 & -0.970 \\
\hline 158 & 410 & 200 & 1135 & 28740 & 388 & 458 & 85 & 124 & 98.3 & 1 & -0.699 \\
\hline 159 & 410 & 200 & 1203 & 36977 & 324 & 391 & 78 & 79 & 87.5 & 1 & -0.073 \\
\hline 160 & 410 & 200 & 1141 & 35081 & 324 & 369 & 73 & 53 & 95.4 & 1 & -0.264 \\
\hline 161 & 410 & 200 & 1164 & 35535 & 332 & 385 & 73 & 80 & 76.5 & -1 & -0.814 \\
\hline 162 & 410 & 200 & 1071 & 29063 & 490 & 362 & 75 & 76 & 72.2 & -1 & -0.947 \\
\hline 163 & 410 & 200 & 1189 & 35820 & 340 & 384 & 78 & 51 & 68.1 & 1 & -0.263 \\
\hline 164 & 410 & 200 & 1101 & 27920 & 485 & 407 & 80 & 93 & 82.1 & -1 & -0.960 \\
\hline 165 & 410 & 200 & 489 & 12504 & 190 & 142 & 36 & 140 & 79.9 & -1 & -0.995 \\
\hline 166 & 410 & 200 & 711 & 16628 & 197 & 315 & 58 & 56 & 49.1 & 1 & 0.406 \\
\hline 167 & 410 & 200 & 879 & 30443 & 119 & 330 & 54 & 40 & 36.9 & 1 & 0.785 \\
\hline 168 & 410 & 200 & 906 & 35094 & 240 & 232 & 48 & 45 & 78.3 & 1 & 0.749 \\
\hline 169 & 410 & 200 & 978 & 36549 & 253 & 216 & 53 & 55 & 84.3 & -1 & -0.389 \\
\hline 170 & 410 & 200 & 858 & 24726 & 240 & 280 & 58 & 51 & 44.3 & 1 & 0.950 \\
\hline 171 & 410 & 200 & 955 & 34522 & 171 & 266 & 55 & 43 & 29.6 & 1 & 0.023 \\
\hline 172 & 410 & 200 & 1071 & 46295 & 215 & 218 & 52 & 45 & 80.1 & 1 & 0.736 \\
\hline 173 & 410 & 200 & 756 & 21452 & 176 & 246 & 53 & 60 & 54.3 & -1 & 0.679 \\
\hline 174 & 410 & 200 & 952 & 30278 & 161 & 252 & 62 & 52 & 80.1 & 1 & 0.772 \\
\hline 175 & 410 & 200 & 995 & 36450 & 240 & 252 & 55 & 44 & 77.4 & 1 & 0.697 \\
\hline 176 & 410 & 200 & 771 & 28371 & 386 & 158 & 40 & 23 & 8.3 & -1 & -0.821 \\
\hline 177 & 410 & 200 & 845 & 36294 & 490 & 177 & 37 & 23 & 53.6 & -1 & 0.159 \\
\hline 178 & 410 & 200 & 658 & 22105 & 328 & 220 & 37 & 28 & 35.5 & 1 & 0.493 \\
\hline 179 & 410 & 200 & 923 & 44398 & 466 & 178 & 38 & 28 & 43.7 & 1 & 0.700 \\
\hline 180 & 410 & 200 & 767 & 27660 & 365 & 155 & 41 & 33 & 55.1 & 1 & 0.224 \\
\hline 181 & 410 & 200 & 661 & 20263 & 368 & 163 & 40 & 30 & 68.5 & -1 & -0.778 \\
\hline 182 & 410 & 200 & 769 & 25348 & 332 & 169 & 44 & 28 & 32.9 & -1 & 0.423 \\
\hline 183 & 410 & 200 & 677 & 16999 & 260 & 159 & 50 & 60 & 74.6 & -1 & -0.702 \\
\hline 184 & 410 & 200 & 1460 & 37666 & 623 & 433 & 105 & 188 & 94.3 & -1 & -0.808 \\
\hline 185 & 410 & 200 & 1389 & 47722 & 583 & 377 & 78 & 100 & 92.8 & -1 & -0.834 \\
\hline 186 & 410 & 200 & 1204 & 36195 & 445 & 372 & 77 & 136 & 96.8 & -1 & -0.914 \\
\hline 187 & 410 & 200 & 1157 & 27182 & 358 & 491 & 93 & 150 & 98.5 & -1 & -0.542 \\
\hline 188 & 410 & 200 & 1042 & 32539 & 509 & 279 & 62 & 121 & 96.9 & -1 & -0.646 \\
\hline 189 & 410 & 200 & 794 & 30454 & 545 & 198 & 63 & 52 & 99.6 & -1 & -0.832 \\
\hline 190 & 410 & 200 & 1052 & 31212 & 371 & 320 & 68 & 121 & 97.3 & 1 & 0.324 \\
\hline 191 & 410 & 200 & 1048 & 31984 & 446 & 310 & 65 & 116 & 97.2 & 1 & -0.377 \\
\hline 192 & 410 & 200 & 1046 & 26748 & 624 & 361 & 73 & 120 & 96.6 & 1 & -0.544 \\
\hline 193 & 410 & 200 & 1148 & 31924 & 490 & 389 & 77 & 131 & 95.1 & -1 & -0.977 \\
\hline 194 & 410 & 200 & 1187 & 36805 & 507 & 369 & 73 & 134 & 97.8 & -1 & -0.879 \\
\hline 195 & 410 & 200 & 910 & 34700 & 58 & 262 & 53 & 49 & 92.3 & -1 & -0.826 \\
\hline 196 & 410 & 200 & 922 & 45803 & 4 & 206 & 46 & 26 & 91.4 & 1 & 0.992 \\
\hline 197 & 410 & 200 & 923 & 42009 & 34 & 239 & 47 & 26 & 86.4 & 1 & 0.964 \\
\hline 198 & 440 & 300 & 1121 & 27245 & 385 & 299 & 137 & 110 & 91.8 & -1 & -0.993 \\
\hline 199 & 440 & 300 & 1452 & 36109 & 473 & 478 & 80 & 92 & 95.8 & -1 & -1.000 \\
\hline 200 & 440 & 300 & 1152 & 25489 & 429 & 397 & 69 & 102 & 96.3 & -1 & -1.000 \\
\hline 201 & 440 & 300 & 1112 & 23294 & 569 & 400 & 66 & 53 & 63.1 & -1 & -1.000 \\
\hline 202 & 440 & 300 & 1447 & 38742 & 520 & 487 & 74 & 64 & 88.4 & -1 & -1.000 \\
\hline 203 & 410 & 200 & 1319 & 28317 & 1345 & 333 & 121 & 67 & 48.3 & 1 & 0.941 \\
\hline 204 & 410 & 200 & 1518 & 32885 & 968 & 466 & 121 & 56 & 52.4 & 1 & 0.733 \\
\hline
\end{tabular}


Table 1. Field behavior data for training set (continued)

(1: damage, -1 : no damage) The shadow determinates the error of prediction

\begin{tabular}{|c|c|c|c|c|c|c|c|c|c|c|c|}
\hline \multirow[t]{2}{*}{ No. } & \multicolumn{2}{|c|}{$\begin{array}{l}\text { Layer } \\
\text { thickness } \\
(\mathrm{mm})\end{array}$} & \multirow{2}{*}{$\begin{array}{c}\text { ISM } \\
(\mathrm{kN} / \mathrm{mm})\end{array}$} & \multicolumn{3}{|c|}{ E modulus (Mpa) } & \multicolumn{2}{|c|}{$\begin{array}{l}\text { Subgrade } \\
\text { reaction } \\
(\mathrm{kPa} / \mathrm{mm})\end{array}$} & \multirow{2}{*}{$\begin{array}{c}\begin{array}{c}\text { Load } \\
\text { transfer }\end{array} \\
(\%)\end{array}$} & \multirow[t]{2}{*}{$\begin{array}{c}\text { Field } \\
\text { behavior }\end{array}$} & \multirow[t]{2}{*}{$\begin{array}{l}\text { Trainning } \\
\text { result }\end{array}$} \\
\hline & PCC & Subbase & & Concrete & Subbase & Subgrade & $\mathrm{kc}$ & $\mathrm{kj}$ & & & \\
\hline 205 & 410 & 200 & 1118 & 28690 & 1077 & 309 & 73 & 81 & 90.2 & -1 & -0.989 \\
\hline 206 & 410 & 200 & 1071 & 40983 & 11 & 236 & 67 & 96 & 97.5 & -1 & -0.976 \\
\hline 207 & 410 & 200 & 987 & 28847 & 128 & 292 & 71 & 83 & 95.3 & 1 & 0.148 \\
\hline 208 & 410 & 200 & 1204 & 26813 & 1283 & 483 & 87 & 44 & 72.7 & -1 & -0.886 \\
\hline 209 & 410 & 200 & 1057 & 22404 & 886 & 251 & 83 & 66 & 84.4 & -1 & -0.976 \\
\hline 210 & 410 & 200 & 1510 & 35227 & 1297 & 326 & 109 & 134 & 93.8 & -1 & -0.935 \\
\hline 211 & 410 & 200 & 831 & 33174 & 22 & 161 & 49 & 49 & 99.5 & 1 & 0.953 \\
\hline 212 & 410 & 200 & 1028 & 43289 & 26 & 213 & 69 & 26 & 12.6 & -1 & -0.991 \\
\hline 213 & 410 & 200 & 1022 & 32127 & 151 & 327 & 68 & 38 & 82.1 & 1 & 0.654 \\
\hline 214 & 410 & 200 & 1433 & 36951 & 760 & 399 & 101 & 90 & 69.1 & 1 & 0.245 \\
\hline 215 & 410 & 200 & 1230 & 29781 & 557 & 418 & 93 & 72 & 78.0 & 1 & -0.387 \\
\hline 216 & 410 & 200 & 1194 & 33115 & 424 & 411 & 82 & 71 & 29.5 & -1 & -0.400 \\
\hline 217 & 410 & 200 & 1070 & 30673 & 360 & 297 & 72 & 65 & 17.4 & -1 & -0.135 \\
\hline 218 & 410 & 200 & 1137 & 32104 & 482 & 379 & 76 & 77 & 63.5 & -1 & -0.887 \\
\hline 219 & 410 & 200 & 1180 & 31577 & 520 & 312 & 82 & 94 & 82.2 & -1 & -0.934 \\
\hline 220 & 380 & 200 & 1179 & 34972 & 638 & 307 & 89 & 81 & 86.9 & -1 & -0.801 \\
\hline 221 & 380 & 200 & 1308 & 44097 & 574 & 329 & 91 & 84 & 36.3 & -1 & -0.988 \\
\hline 222 & 380 & 200 & 1526 & 37634 & 760 & 511 & 137 & 100 & 54.2 & -1 & -0.388 \\
\hline 223 & 380 & 200 & 1072 & 35568 & 724 & 298 & 72 & 77 & 84.8 & 1 & -0.049 \\
\hline 224 & 380 & 200 & 1209 & 29125 & 495 & 566 & 113 & 113 & 29.1 & 1 & 0.771 \\
\hline 225 & 380 & 200 & 1265 & 35163 & 754 & 387 & 100 & 95 & 42.8 & -1 & -0.650 \\
\hline 226 & 380 & 200 & 1468 & 36965 & 912 & 398 & 126 & 131 & 83.8 & 1 & 0.628 \\
\hline 227 & 410 & 200 & 1479 & 28781 & 1095 & 388 & 127 & 133 & 82.4 & 1 & 0.777 \\
\hline 228 & 410 & 200 & 1532 & 35282 & 800 & 426 & 119 & 142 & 85.9 & 1 & 0.872 \\
\hline 229 & 410 & 200 & 1548 & 36716 & 814 & 452 & 117 & 81 & 16.1 & 1 & 0.909 \\
\hline 230 & 380 & 200 & 1051 & 33191 & 338 & 315 & 80 & 56 & 40.0 & 1 & 0.272 \\
\hline 231 & 380 & 200 & 1314 & 29777 & 320 & 677 & 137 & 144 & 90.1 & 1 & 0.970 \\
\hline 232 & 380 & 200 & 780 & 25192 & 339 & 198 & 56 & 67 & 89.9 & 1 & 0.720 \\
\hline 233 & 380 & 200 & 995 & 33802 & 342 & 267 & 70 & 68 & 20.7 & 1 & 0.470 \\
\hline 234 & 380 & 200 & 1196 & 35312 & 678 & 350 & 90 & 84 & 86.8 & -1 & -0.907 \\
\hline 235 & 380 & 200 & 1177 & 32570 & 433 & 426 & 99 & 62 & 89.6 & 1 & 0.701 \\
\hline 236 & 410 & 200 & 1166 & 34224 & 489 & 321 & 75 & 91 & 79.3 & 1 & -0.473 \\
\hline 237 & 410 & 200 & 1030 & 28589 & 428 & 294 & 70 & 86 & 30.3 & -1 & -0.288 \\
\hline 238 & 410 & 200 & 1051 & 29556 & 557 & 301 & 68 & 86 & 94.6 & -1 & -0.416 \\
\hline 239 & 410 & 200 & 1276 & 28727 & 475 & 407 & 105 & 120 & 34.5 & 1 & 0.919 \\
\hline 240 & 410 & 200 & 1268 & 30815 & 724 & 508 & 93 & 97 & 70.8 & -1 & -0.903 \\
\hline 241 & 410 & 200 & 1208 & 40930 & 659 & 324 & 67 & 54 & 37.1 & 1 & 0.710 \\
\hline 242 & 410 & 200 & 1244 & 30143 & 725 & 437 & 91 & 83 & 35.9 & -1 & -0.332 \\
\hline 243 & 410 & 200 & 1254 & 31465 & 545 & 466 & 92 & 102 & 31.5 & 1 & 0.140 \\
\hline 244 & 410 & 200 & 1319 & 35266 & 551 & 445 & 92 & 84 & 88.7 & -1 & -0.137 \\
\hline 245 & 410 & 200 & 1446 & 47971 & 493 & 436 & 85 & 91 & 70.4 & -1 & -0.851 \\
\hline 246 & 410 & 200 & 1248 & 31555 & 365 & 442 & 95 & 116 & 78.8 & -1 & -0.647 \\
\hline 247 & 410 & 200 & 1365 & 36351 & 550 & 413 & 96 & 133 & 79.7 & -1 & -0.788 \\
\hline 248 & 410 & 200 & 1254 & 32306 & 397 & 497 & 93 & 66 & 94.6 & 1 & 0.909 \\
\hline 249 & 410 & 200 & 1261 & 34181 & 557 & 361 & 87 & 95 & 76.3 & -1 & -0.951 \\
\hline 250 & 410 & 200 & 1276 & 28936 & 850 & 418 & 97 & 98 & 74.7 & 1 & 0.338 \\
\hline 251 & 410 & 200 & 1310 & 38386 & 586 & 442 & 84 & 88 & 82.9 & 1 & -0.374 \\
\hline 252 & 410 & 200 & 1564 & 43311 & 699 & 638 & 105 & 123 & 71.7 & 1 & 0.805 \\
\hline 253 & 410 & 200 & 1227 & 31218 & 517 & 395 & 90 & 84 & 67.3 & -1 & -0.595 \\
\hline 254 & 410 & 200 & 1394 & 51331 & 421 & 431 & 76 & 125 & 98.4 & 1 & 0.628 \\
\hline 255 & 410 & 200 & 1310 & 47915 & 605 & 349 & 69 & 118 & 99.7 & 1 & 0.299 \\
\hline
\end{tabular}


Table 1. Field behavior data for training set (continued)

(1: damage, $-1:$ no damage) The shadow determinates the error of prediction

\begin{tabular}{|c|c|c|c|c|c|c|c|c|c|c|c|}
\hline \multirow[t]{2}{*}{ No. } & \multicolumn{2}{|c|}{$\begin{array}{l}\text { Layer } \\
\text { thickness } \\
(\mathrm{mm})\end{array}$} & \multirow{2}{*}{$\begin{array}{c}\mathrm{ISM} \\
(\mathrm{kN} / \mathrm{mm})\end{array}$} & \multicolumn{3}{|c|}{ E modulus (Mpa) } & \multicolumn{2}{|c|}{$\begin{array}{l}\text { Subgrade } \\
\text { reaction } \\
(\mathrm{kPa} / \mathrm{mm})\end{array}$} & \multirow{2}{*}{$\begin{array}{c}\begin{array}{c}\text { Load } \\
\text { transfer }\end{array} \\
(\%)\end{array}$} & \multirow[t]{2}{*}{$\begin{array}{c}\text { Field } \\
\text { behavior }\end{array}$} & \multirow[t]{2}{*}{$\begin{array}{l}\text { Trainning } \\
\text { result }\end{array}$} \\
\hline & PCC & Subbase & & Concrete & Subbase & Subgrade & $\mathrm{kc}$ & $\mathrm{kj}$ & & & \\
\hline 256 & 410 & 200 & 1533 & 41559 & 586 & 516 & 107 & 166 & 97.5 & 1 & 0.847 \\
\hline 257 & 410 & 200 & 1378 & 40614 & 627 & 490 & 88 & 165 & 95.9 & -1 & -0.915 \\
\hline 258 & 410 & 200 & 1326 & 41798 & 460 & 477 & 82 & 151 & 98.0 & -1 & -0.674 \\
\hline 259 & 410 & 200 & 1397 & 42786 & 436 & 458 & 89 & 138 & 97.3 & 1 & 0.538 \\
\hline 260 & 410 & 200 & 1259 & 35553 & 550 & 424 & 83 & 172 & 96.2 & -1 & -0.962 \\
\hline 261 & 410 & 200 & 1484 & 43043 & 658 & 572 & 96 & 154 & 96.7 & 1 & 0.921 \\
\hline 262 & 380 & 200 & 824 & 27938 & 593 & 202 & 54 & 78 & 81.5 & -1 & -0.933 \\
\hline 263 & 380 & 200 & 1193 & 39164 & 585 & 292 & 84 & 97 & 85.5 & -1 & -0.405 \\
\hline 264 & 380 & 200 & 1022 & 30203 & 532 & 304 & 78 & 82 & 82.3 & -1 & -0.270 \\
\hline 265 & 410 & 200 & 994 & 23567 & 443 & 367 & 77 & 99 & 82.3 & -1 & -0.702 \\
\hline 266 & 410 & 200 & 1197 & 28099 & 789 & 343 & 89 & 116 & 80.4 & -1 & -0.996 \\
\hline 267 & 410 & 200 & 1162 & 20411 & 1596 & 289 & 99 & 195 & 66.1 & -1 & -0.917 \\
\hline 268 & 410 & 200 & 1137 & 29210 & 709 & 288 & 79 & 90 & 77.9 & -1 & -0.927 \\
\hline 269 & 450 & 300 & 1575 & 31238 & 735 & 458 & 94 & 90 & 91.5 & -1 & -1.000 \\
\hline 270 & 450 & 300 & 1084 & 23582 & 400 & 297 & 62 & 77 & 88.4 & -1 & -1.000 \\
\hline 271 & 450 & 300 & 1249 & 35569 & 710 & 395 & 53 & 56 & 47.2 & -1 & -0.997 \\
\hline 272 & 450 & 300 & 1575 & 31238 & 735 & 458 & 94 & 90 & 91.5 & -1 & -1.000 \\
\hline 273 & 450 & 300 & 1102 & 23925 & 760 & 396 & 57 & 63 & 65.7 & -1 & -0.999 \\
\hline 274 & 450 & 300 & 1153 & 24264 & 306 & 447 & 71 & 77 & 90.6 & -1 & -0.999 \\
\hline 275 & 410 & 200 & 1043 & 39335 & 543 & 249 & 55 & 37 & 46.2 & -1 & -0.190 \\
\hline 276 & 410 & 200 & 1133 & 45290 & 495 & 282 & 56 & 51 & 58.0 & -1 & -0.863 \\
\hline 277 & 410 & 200 & 1261 & 37393 & 543 & 408 & 80 & 76 & 51.7 & 1 & 0.449 \\
\hline 278 & 410 & 200 & 1190 & 30965 & 335 & 470 & 96 & 85 & 47.4 & -1 & -0.947 \\
\hline 279 & 410 & 200 & 1278 & 32174 & 461 & 522 & 70 & 69 & 56.6 & -1 & -0.737 \\
\hline 280 & 410 & 200 & 1203 & 35592 & 446 & 365 & 78 & 78 & 50.7 & -1 & -0.782 \\
\hline
\end{tabular}

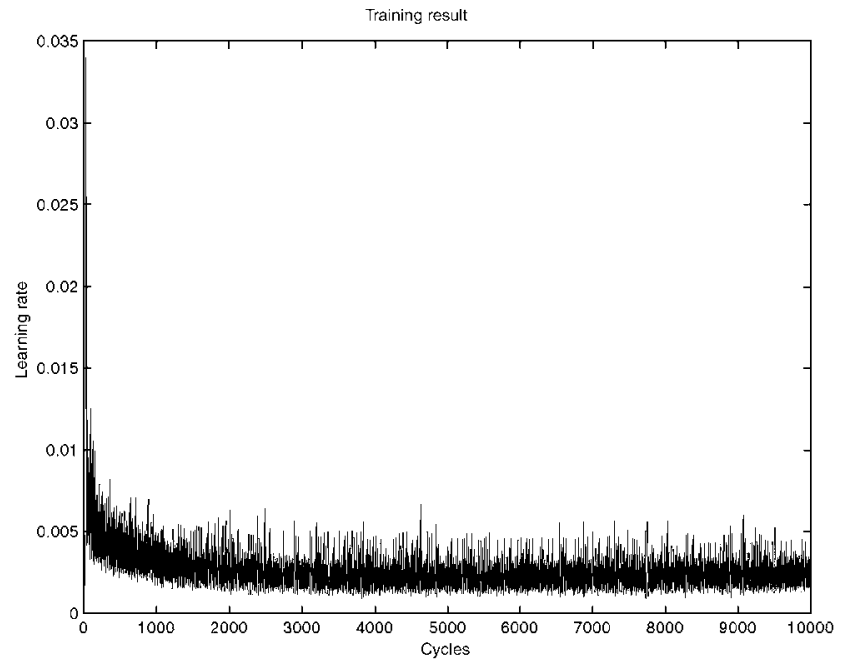

Fig. 6. Learning rate of neuro-fuzzy system.

data to improve the accuracy.

Besides those parameters adopted in this paper,

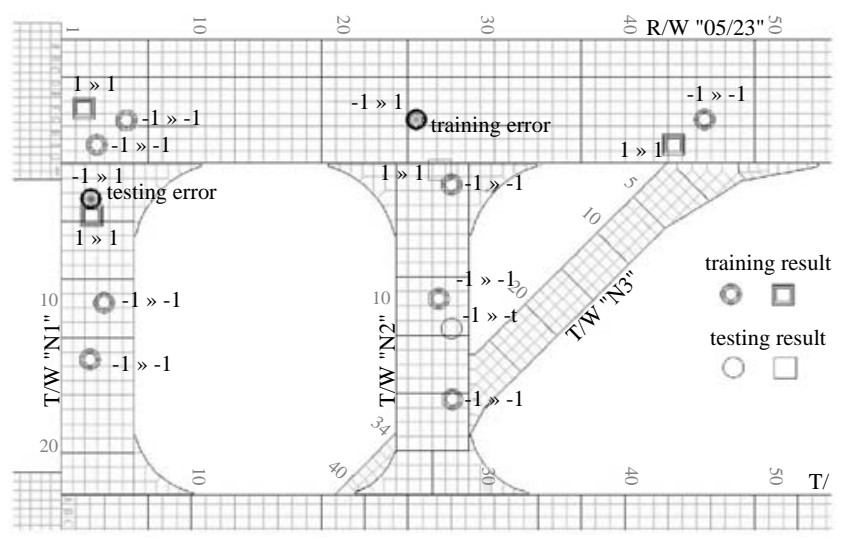

Fig. 7. Part drawing of training and testing results at runway threshold area.

the other factors, such as PCC slab warping and curling, moisture contents in each of the layers, voids, loss of support, settlement occurred beneath the pavement layer, all of them also influence the deflection basins and get 
Table 2. Field behavior data for testing set

\begin{tabular}{|c|c|c|c|c|c|c|c|c|c|c|c|}
\hline \multirow[t]{2}{*}{ No. } & \multicolumn{2}{|c|}{$\begin{array}{l}\text { Layer } \\
\text { thickness } \\
(\mathrm{mm})\end{array}$} & \multirow{2}{*}{$\begin{array}{c}\text { ISM } \\
(\mathrm{kN} / \mathrm{mm})\end{array}$} & \multicolumn{3}{|c|}{ E modulus (Mpa) } & \multicolumn{2}{|c|}{$\begin{array}{l}\text { Subgrade } \\
\text { reaction } \\
(\mathrm{kPa} / \mathrm{mm})\end{array}$} & \multirow{2}{*}{$\begin{array}{l}\text { Load } \\
\text { transfer }\end{array}$} & \multirow[t]{2}{*}{$\begin{array}{c}\text { Field } \\
\text { behavior }\end{array}$} & \multirow[t]{2}{*}{$\begin{array}{c}\text { Testing } \\
\text { result }\end{array}$} \\
\hline & PCC & Subbase & & Concrete & Subbase & Subgrade & $\mathrm{kc}$ & $\mathrm{kj}$ & & & \\
\hline 1 & 380 & 200 & 987 & 28228 & 484 & 346 & 78 & 66 & 22.9 & -1 & -0.437 \\
\hline 2 & 380 & 200 & 1288 & 29697 & 1047 & 537 & 115 & 34 & 61.6 & 1 & 0.612 \\
\hline 3 & 380 & 200 & 1282 & 40569 & 590 & 372 & 93 & 61 & 99.5 & -1 & -0.517 \\
\hline 4 & 380 & 200 & 1115 & 32380 & 447 & 419 & 89 & 60 & 91.1 & 1 & 0.981 \\
\hline 5 & 380 & 200 & 1161 & 35303 & 661 & 341 & 85 & 111 & 93.7 & 1 & 0.129 \\
\hline 6 & 380 & 200 & 831 & 25962 & 444 & 233 & 60 & 132 & 95.8 & 1 & -0.922 \\
\hline 7 & 380 & 200 & 940 & 27622 & 495 & 277 & 72 & 101 & 98.3 & 1 & -0.496 \\
\hline 8 & 380 & 200 & 1316 & 37401 & 743 & 479 & 103 & 67 & 95.2 & -1 & 0.426 \\
\hline 9 & 410 & 200 & 1282 & 34408 & 432 & 370 & 91 & 124 & 88.4 & -1 & -0.784 \\
\hline 10 & 380 & 200 & 1058 & 33227 & 1098 & 267 & 69 & 95 & 74.2 & -1 & -0.951 \\
\hline 11 & 380 & 200 & 1108 & 31757 & 752 & 323 & 84 & 95 & 82.6 & 1 & -0.157 \\
\hline 12 & 410 & 200 & 1364 & 29446 & 627 & 537 & 114 & 93 & 82.3 & -1 & 0.801 \\
\hline 13 & 410 & 200 & 1114 & 35732 & 477 & 282 & 66 & 46 & 97.6 & 1 & 0.301 \\
\hline 14 & 410 & 200 & 1246 & 33681 & 557 & 347 & 86 & 90 & 92.1 & -1 & -0.914 \\
\hline 15 & 380 & 200 & 960 & 29527 & 602 & 312 & 69 & 78 & 94.0 & -1 & -0.482 \\
\hline 16 & 380 & 200 & 868 & 25923 & 356 & 338 & 67 & 80 & 92.4 & -1 & -0.661 \\
\hline 17 & 410 & 200 & 897 & 34573 & 495 & 172 & 44 & 67 & 48.4 & -1 & 0.844 \\
\hline 18 & 410 & 200 & 725 & 23381 & 405 & 176 & 42 & 81 & 95.6 & 1 & -0.949 \\
\hline 19 & 410 & 200 & 819 & 28324 & 490 & 188 & 44 & 26 & 86.5 & -1 & -0.845 \\
\hline 20 & 380 & 200 & 1245 & 43155 & 705 & 326 & 82 & 125 & 96.8 & -1 & 0.164 \\
\hline 21 & 380 & 200 & 1033 & 30431 & 584 & 276 & 78 & 92 & 98.6 & -1 & -0.197 \\
\hline 22 & 410 & 200 & 1211 & 29468 & 490 & 495 & 92 & 90 & 98.5 & -1 & -0.075 \\
\hline 23 & 380 & 200 & 914 & 30990 & 507 & 275 & 61 & 74 & 95.5 & 1 & -0.820 \\
\hline 24 & 380 & 200 & 1215 & 43938 & 461 & 414 & 80 & 107 & 97.8 & 1 & 0.927 \\
\hline 25 & 380 & 200 & 1087 & 34502 & 277 & 443 & 84 & 58 & 20.3 & 1 & -0.911 \\
\hline 26 & 380 & 200 & 1138 & 39130 & 340 & 378 & 81 & 60 & 91.0 & 1 & 0.880 \\
\hline 27 & 380 & 200 & 1256 & 41300 & 340 & 491 & 93 & 57 & 80.1 & 1 & 0.661 \\
\hline 28 & 380 & 200 & 972 & 31452 & 495 & 270 & 69 & 81 & 43.0 & -1 & -0.647 \\
\hline 29 & 380 & 200 & 1284 & 35305 & 586 & 462 & 106 & 88 & 42.6 & -1 & -0.656 \\
\hline 30 & 380 & 200 & 1275 & 38012 & 1100 & 366 & 90 & 65 & 97.9 & 1 & 0.005 \\
\hline 31 & 410 & 200 & 1102 & 28350 & 694 & 356 & 76 & 123 & 97.2 & -1 & -0.736 \\
\hline 32 & 410 & 200 & 1149 & 33769 & 357 & 370 & 76 & 129 & 98.2 & -1 & -0.896 \\
\hline 33 & 410 & 200 & 1111 & 34446 & 308 & 360 & 72 & 89 & 97.0 & -1 & -0.539 \\
\hline 34 & 410 & 200 & 811 & 26417 & 184 & 297 & 50 & 46 & 49.2 & 1 & 0.948 \\
\hline 35 & 410 & 200 & 912 & 32664 & 208 & 274 & 52 & 40 & 56.5 & -1 & 0.982 \\
\hline 36 & 410 & 200 & 767 & 22944 & 333 & 183 & 48 & 30 & 49.3 & 1 & 0.738 \\
\hline 37 & 410 & 200 & 1384 & 38776 & 376 & 452 & 99 & 99 & 96.2 & -1 & 0.094 \\
\hline 38 & 410 & 200 & 1139 & 35633 & 388 & 368 & 71 & 116 & 97.8 & 1 & -0.495 \\
\hline 39 & 440 & 300 & 1359 & 25575 & 429 & 573 & 95 & 50 & 91.3 & -1 & -0.997 \\
\hline 40 & 410 & 200 & 1201 & 30157 & 235 & 486 & 96 & 98 & 98.6 & 1 & 0.706 \\
\hline 41 & 410 & 200 & 1111 & 30717 & 802 & 298 & 71 & 69 & 86.6 & -1 & -0.572 \\
\hline 42 & 410 & 200 & 1307 & 32072 & 450 & 453 & 101 & 105 & 82.1 & -1 & -0.003 \\
\hline 43 & 380 & 200 & 871 & 33357 & 208 & 237 & 57 & 52 & 89.7 & -1 & -0.897 \\
\hline 44 & 380 & 200 & 1154 & 32167 & 676 & 436 & 91 & 78 & 16.9 & 1 & 0.889 \\
\hline 45 & 410 & 200 & 1382 & 39941 & 688 & 463 & 88 & 103 & 87.3 & -1 & -0.069 \\
\hline 46 & 410 & 200 & 1225 & 31827 & 485 & 347 & 88 & 89 & 65.1 & 1 & -0.850 \\
\hline 47 & 410 & 200 & 1165 & 48652 & 431 & 304 & 55 & 85 & 96.9 & 1 & -0.647 \\
\hline 48 & 380 & 200 & 1155 & 35337 & 550 & 271 & 86 & 111 & 48.5 & -1 & -0.651 \\
\hline 49 & 250 & 200 & 498 & 20111 & 743 & 197 & 70 & 79 & 76.4 & 1 & -0.917 \\
\hline 50 & 410 & 200 & 1183 & 36243 & 488 & 369 & 73 & 78 & 57.2 & -1 & -0.860 \\
\hline 51 & 410 & 200 & 1208 & 33964 & 436 & 397 & 78 & 75 & 57.6 & -1 & -0.446 \\
\hline
\end{tabular}


Table 3. Error of prediction

\begin{tabular}{cccc}
\hline & $\begin{array}{c}\text { Actual behavior: } \\
\text { damage } \\
\text { Model prediction: } \\
\text { No damage (\%) }\end{array}$ & $\begin{array}{c}\text { Actual behavior: } \\
\text { No damage } \\
\text { Model prediction: } \\
\text { damage (\%) }\end{array}$ & Success rate(\%) \\
\hline $\begin{array}{c}\text { Training set } \\
\left(113^{*} \text { 167*) }\right.\end{array}$ Testing set & 8.2 & 1.8 & 90.0 \\
$\left(22^{*} 29 *\right)$ & 19.6 & 11.8 & 68.6 \\
\hline
\end{tabular}

*Actual pavement behavior: no damage

**Actual pavement behavior: damage

Table 4. Pavement surface condition of testing data

\begin{tabular}{|c|c|c|c|c|c|c|c|c|c|c|c|}
\hline No. & $\begin{array}{c}\text { Field } \\
\text { behavior }\end{array}$ & $\begin{array}{c}\text { Testing } \\
\text { result }\end{array}$ & $\begin{array}{l}\text { Longitudinal } \\
\text { cracks }\end{array}$ & $\begin{array}{l}\text { Transverse } \\
\text { cracks }\end{array}$ & $\begin{array}{l}\text { Corner } \\
\text { breaks }\end{array}$ & $\begin{array}{l}\text { Durability } \\
\text { cracks }\end{array}$ & $\begin{array}{l}\text { Joint } \\
\text { spalling }\end{array}$ & $\begin{array}{l}\text { Pumping } \\
\text { sealant loss }\end{array}$ & Blow-up Faulting Polishing & Pothole & Patch \\
\hline 1 & -1 & -0.437 & & & & & & & & & \\
\hline 2 & 1 & 0.612 & & & & & & 1 & & & 1 \\
\hline 3 & -1 & -0.517 & & & & & & & & & \\
\hline 4 & 1 & 0.981 & & & & & & & & & 3 \\
\hline 5 & 1 & 0.129 & & & & & & 1 & & & 1 \\
\hline 6 & 1 & -0.922 & & & & & & 1 & & & $\begin{array}{l}1 \\
2\end{array}$ \\
\hline 7 & 1 & -0.496 & & & & & & 2 & & & \\
\hline 8 & -1 & 0.426 & & & & & & & & & \\
\hline 9 & -1 & -0.784 & & & & & & & & & \\
\hline 10 & -1 & -0.951 & & & & & & & & & \\
\hline 11 & 1 & -0.157 & & & & & & & & & 2 \\
\hline 12 & -1 & 0.801 & & & & & & & & & \\
\hline 13 & $\begin{array}{r}-1 \\
1\end{array}$ & 0.301 & & & & & 1 & & & 1 & \\
\hline 14 & -1 & -0.914 & & & & & & & & & \\
\hline 15 & -1 & -0.482 & & & & & & & & & \\
\hline 16 & -1 & -0.661 & & & & & & & & & \\
\hline 17 & -1 & 0.844 & & & & & & & & & \\
\hline 18 & 1 & -0.949 & & & & & & & & & 1 \\
\hline 19 & -1 & -0.845 & & & & & & & & & \\
\hline 20 & -1 & 0.164 & & & & & & & & & \\
\hline 21 & -1 & -0.197 & & & & & & & & & \\
\hline 22 & -1 & -0.075 & & & & & & & & & \\
\hline 23 & 1 & -0.820 & & & & & & & & & 1 \\
\hline 24 & 1 & 0.927 & & & & & & & & & 1 \\
\hline 25 & 1 & -0.911 & & & & & & & & 1 & \\
\hline 26 & 1 & 0.880 & & & & & & & & & 1 \\
\hline 27 & 1 & 0.661 & & & & & & & & & 1 \\
\hline 28 & -1 & -0.647 & & & & & & & & & \\
\hline 29 & -1 & -0.656 & & & & & & & & & \\
\hline 30 & 1 & 0.005 & 2 & & & & & & & & 1 \\
\hline 31 & -1 & -0.736 & & & & & & & & & \\
\hline 32 & -1 & -0.896 & & & & & & & & & \\
\hline 33 & -1 & -0.539 & & & & & & & & & \\
\hline 34 & 1 & 0.948 & & & & & & & & & 1 \\
\hline 35 & -1 & 0.982 & & & & & 1 & & & & \\
\hline 36 & 1 & 0.738 & & & & & & & & & \\
\hline 37 & -1 & 0.094 & & & & & & & & & \\
\hline 38 & 1 & -0.495 & & & & & & & & & 3 \\
\hline 39 & -1 & -0.997 & & & & & & & & & \\
\hline 40 & 1 & 0.706 & & & & & & & & & 1 \\
\hline 41 & -1 & -0.572 & & & & & & & & & \\
\hline 42 & -1 & -0.003 & & & & & & & & & \\
\hline 43 & -1 & -0.897 & & & & & & & & & \\
\hline 44 & 1 & 0.889 & & & & & & & & & 1 \\
\hline 45 & -1 & -0.069 & & & & & & & & & \\
\hline 46 & 1 & -0.850 & & & & & & & 1 & & \\
\hline 47 & 1 & -0.647 & & & & & & & & & 2 \\
\hline 48 & -1 & -0.651 & & & & & & & & & \\
\hline 49 & 1 & -0.917 & & & 1 & & 1 & & 2 & & \\
\hline 50 & -1 & -0.860 & & & & & & & & & \\
\hline 51 & -1 & -0.446 & & & & & & & & & \\
\hline
\end{tabular}


different results. But, in fact, it is not easy to collect those data from all pavement slabs. Such as slab curling occurs due to differences in temperature between the top and bottom of the slab, the slab corners may lift off the base during nighttime curling, and slab center may lift off during daytime curling.

However, it seems the model combing a nondestructive testing and a neuro-fuzzy system is an economical way to evaluate rigid pavement failure potential between the service performance and the structure performance.

\section{ACKNOWLEDGEMENTS}

The authors would to thank the supports of the Chiang Kai-Shek International airport authority for their data and serves that were used in this research.

\section{REFERENCES}

1. Abu, K.M.A., "General Regression Neural Networks for Driven Piles in Cohesionless Soils," J. Geotech. Geoenviron., Vol. 124, No. 12, pp. 177-1185 (1998).

2. ASTM, "D4695 Standard Test Method of Deflections with a Falling Weight Type Impulse Load Device," Vol. 4.03, Sec. 4, pp. $482-484$ (1996).

3. ASTM, "D5340 Standard Test Method for Airport Pavement Condition Index Survey," Vol. 4.03, Sec. 4, pp. 552-599 (1996).

4. ASTM, "Standard Guide for General Pavement Deflection Measurement," D4695-96, pp. 485-487 (1996).

5. Boutros, E.S., Mamlouk, M.S., and Trevor, G.P., "Dynamic Analysis of Falling Weight Deflectometer Data," Transportat. Res. Rec. 1070, pp. 63-68 (1986).

6. Bush III, A.J. and Alexander, D.R., "Pavement Evaluation Using Deflection Basin Measurements and Layered Theory," Transport. Res. Rec. 1022, pp. 16-29 (1985).

7. Chang, D.W., Kang, V.Y., Roesset, J.M., and Stokoe, K.H., "Effects of Depth to Bedrock on Deflection Basins Obtained with Dynaflect FWD Test," Transport. Res. Rec. 1355, pp. 8-16 (1992).

8. Chern, S.G., Hu, R.F., Chang, Y.J., and Tsai, I.F., "FuzzART Neural Networks for Predicting Chi-Chi Earthquake Induced Liquefaction in Yuan-Lin Area," J. Mar. Sci. Technol., Vol. 10, No. 1 (2002).

9. Dater, M.I., Smith, K.D., and Hall, K.T., "Concrete Pavement Backcalculation Results from Field Studies," Transport. Res. Rec. 1377, pp. 7-16 (1993).

10. Ellis, G.W., Yao, C., Zhao, R., and Penumadu, D., "Stress-Strain Modeling of Sands Using Artificial Neural Networks," J. Geotech. Eng., Vol. 121, No. 5, pp. 429-435 (1995).
11. Fred, F., "Pavement Management Systems -Past, Present and Future," Public Roads, Vol. 62, No. 1, pp. 16-23 (1998).

12. Goh, A.T.C., "Seismic Liquefaction Potential Assessed by Neural Network," J. Geotech. Eng., Vol. 120, No. 9, pp. 1467-1480 (1994).

13. Huang, Y.H., Pavement Analysis and Design, PrenticeHall, Inc., Englewood Cliffs, NJ (1993).

14. Jang, J.S., Sun, C.T., and Mizutani, E., Neural-Fuzzy and Soft Computing, Prentice-Hall, Inc., Englewood Cliffs, NJ (1997).

15. Johnson, R.F. and Rish III J.W., "Rolling Weight Deflectometer with Thermal and Vibrational Bending Compensation," Transport. Res. Rec. 1540, pp. 77-82 (1996).

16. Juang, C.H., Chen, C.J., and Tien, Y.M., “Appraising CPT-Based Liquefaction Resistance Evaluation Methods: Artificial Neural Networks Approach," Can. Geotech. J., Vol. 36, No 3, pp. 443-454 (1999).

17. Juang, C.H., Lee, D.H., and Sheu, C., "Mapping Slope Failure Potential Using Fuzzy Sets," J. Geotech. Eng., Vol. 118, No. 3, pp. 475-494 (1992).

18. Kulkarni, A.D., Computer Vision and Fuzzy-Neural Systems, Prentice-Hall, Inc., Englewood Cliffs, NJ (2001).

19. Mario, S.G. and Jim, W.H., "Comparative Study of Selected Non-destructive Testing Devices," Transport. Res. Rec. 852, pp. 32-71 (1974).

20. Ni, S.H., Lu, P.C., and Juang, C.H., "A Fuzzy Neural Network Approach to Evaluation of Slope Failure Potential," Microcomput. Civil Eng., Vol. 11, pp. 59-66 (1996).

21. Schwandt, G., "Airport Pavement Management System Saves Millions," Public Works, Vol. 127, No. 1, pp. 5355 (1996).

22. Tung, A.T.Y., Wang, Y.Y., and Wong, F.S., "Assessment of Liquefaction Potential Using Neural Networks," Soil Dyn. Earthq. Eng., Vol. 12, No. 6, pp. 325-333 (1993).

23. Ullidtz, P. and Coetzee, N.F., "Analytical Procedure in Nondestructive Testing Pavement Evaluation," Transport. Res. Rec. 1482, pp. 61-66 (1995).

24. U.S. Department of Transportation, Federal Aviation Administration, Use of Nondestructive Testing in The Evaluation of Airport Pavement (FAA/AC 150/537011B), Washington, DC (2003).

25. Weil, G.J., "Non-destructive Testing of Bridge, Highway and Airport Pavements," Geol. Surv. Finland, Vol. 16, pp. 259-266 (1992).

26. Yang, C.H., Wang, C.Y., and Ko, C.M., "Detecting the Structure of Flexible Pavement Using Ground Penetrating Radar," NDT Sci. Technol., Vol. 18, No. 2, pp. 44-53 (2000). (in Chinese) 